Review

\title{
Theoretical and practical considerations behind the use of laboratory animals for the study of Tourette syndrome
}

\author{
Simone Macrì, Martina Proietti Onori, Giovanni Laviola* \\ Section of Behavioural Neuroscience, Dep. Cell Biology \& Neuroscience, Istituto Superiore di Sanità, Rome, Italy
}

\section{A R T I C L E I N F O}

\section{Article history:}

Received 5 November 2012

Received in revised form 19 March 2013

Accepted 23 March 2013

\section{Keywords:}

Animal models

Risk factors

Tics

Stereotypies

Abnormal repetitive behaviors

Basal Ganglia

\begin{abstract}
A B S T R A C T
In the present manuscript we review a substantial body of literature describing several pre-clinical animal models designed and developed with the purpose of investigating the biological determinants of Tourette syndrome (TS). In order to map the animal models onto the theoretical background upon which they have been devised, we first define phenomenological and etiological aspects of TS and then match this information to the available pre-clinical models. Thus, we first describe the characteristic symptoms exhibited by TS patients and then a series of hypotheses attempting to identify the multifactorial causes of TS. With respect to the former, we detail the phenomenology of abnormal repetitive behaviors (tics and stereotypies), obsessive-compulsive behaviors and aberrant sensory-motor gating. With respect to the latter, we describe both potential candidate vulnerability genes and environmental factors (difficult pregnancies, psychosocial stressors and infections). We then discuss how this evidence has been translated in pre-clinical research with respect to both dependent (symptoms) and independent (etiological factors) variables. Thus, while, on the one hand, we detail the methodologies adopted to measure abnormal repetitive and obsessive-compulsive behaviors, and sensory-motor gating, on the other hand, we describe genetic engineering studies and environmental modulations aimed at reproducing the proposed biological determinants in laboratory rodents. A special emphasis is placed upon "programming" events, occurring during critical stages of early development and exerting organizational delayed consequences. In the final section, we outline a heuristic model with the purpose of integrating clinical and pre-clinical evidence in the study of TS.
\end{abstract}

(C) 2013 Elsevier Ltd. All rights reserved.

\section{Contents}

1. Introduction

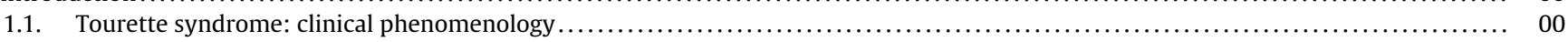

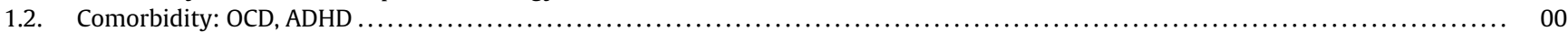

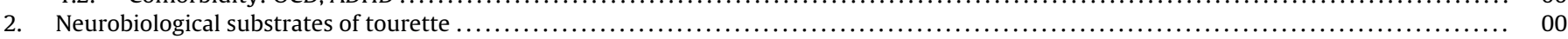

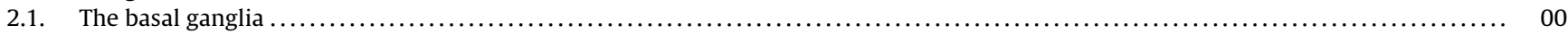

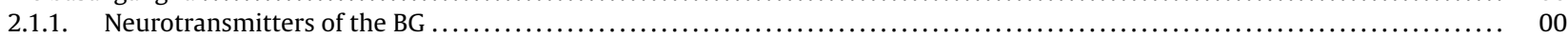

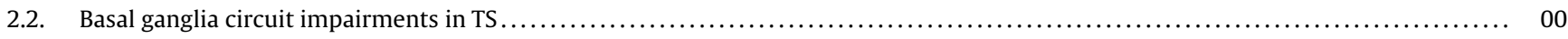

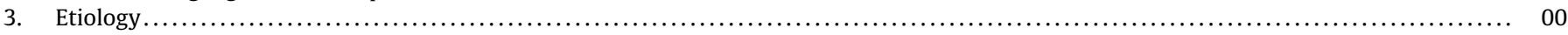

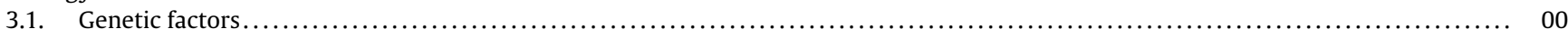

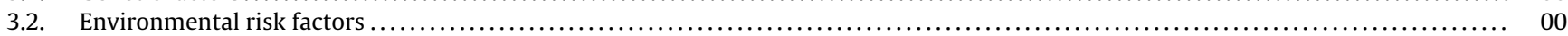

Abbreviations: 5-HT, serotonin; ADHD, attention deficit hyperactivity disorder; ARB, abnormal repetitive behavior; BDNF, brain-derived neurotrophic factor; BG, basal ganglia; CNTNAP2, contactin-associated protein-like 2; CRF, corticotrophin releasing factor; CSTC, cortico - striatal - thalamocortical; DA, dopamine; DAT, dopamine transporter; GABA, gamma-aminobutyric acid; GABHS, group A $\beta$-hemolytic streptococcus; GAS, group A streptococcus; GPe, globus pallidus externa; GPi, globus pallidus interna; HDC, L-histidine Decarboxylase; HPA, hypothalamic-pituitary-adrenal; IL-12, interleukin 12; IMMP2L, inner mitochondrial membrane peptidase 2 like; NA, norepinephrine; NLGN4X, neuroligin-4, X-linked; OCD, obsessive - compulsive disorder; PANDAS, pediatric autoimmune neuropsychiatric disorders associated with streptococcal; PPI, prepulse inhibition; SERT, serotonin transporter; SLITRK1, SLIT and NTRK-like 1; SNc, substantia nigra pars compacta; SNr, substantia nigra pars reticulata; STN, subthalamic nucleus; TNF- $\alpha$, tumor necrosis factor alpha; TS, Tourette syndrome.

* Corresponding author at: Sect. Behavioural Neuroscience, Dept. Cell Biology \& Neuroscience, Istituto Superiore di Sanità, Viale Regina Elena, 299, I-00161 Roma, EU, Italy. Tel.: +39064990 2105; fax: +3906495 7821.

E-mail address: giovanni.laviola@iss.it (G. Laviola).

0149-7634/\$ - see front matter @ 2013 Elsevier Ltd. All rights reserved. http://dx.doi.org/10.1016/j.neubiorev.2013.03.014 


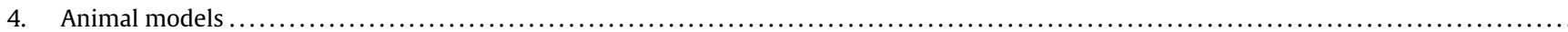

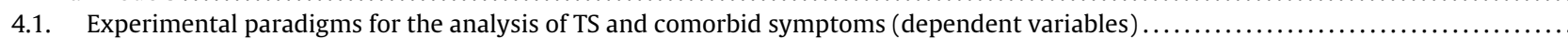

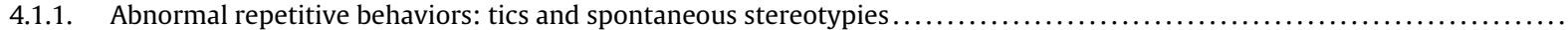

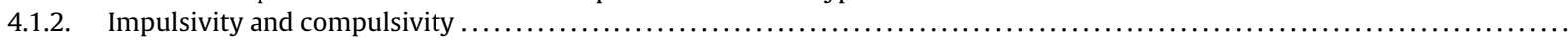

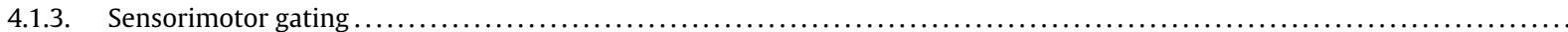

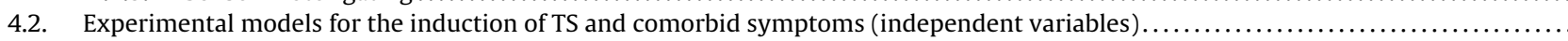

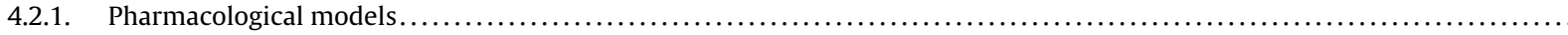

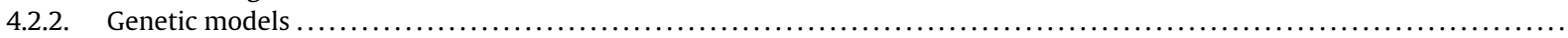

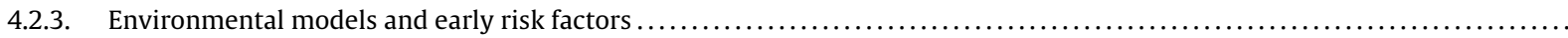

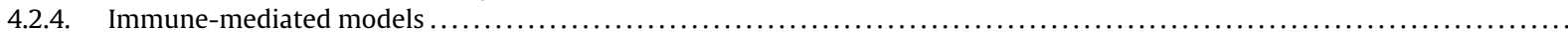

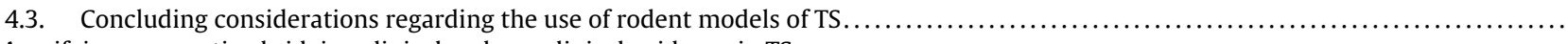

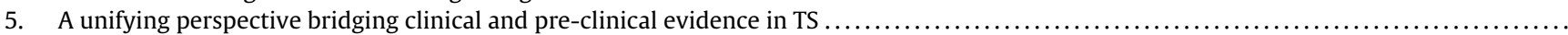

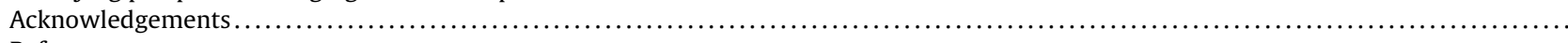

References

\section{Introduction}

"While Tourette's may be considered, like Parkinsonism, a movement disorder (albeit of an explosive rather than an obstructive kind), it is much more. It has a mind of its own. Tourette's is impulsive, productive. .."(Sacks, 2008). So does Oliver Sacks encapsulate the essence of Tourette syndrome (TS). The explosive nature of the symptoms is highly debilitating from its origin, whereby children exhibiting TS-typical behavioral abnormalities easily attract "savage ridicule and bullying from [his] schoolmates". Thus, while becoming embodied in patients' habits and conduct, TS strongly interferes with individual daily life. Understanding its biological determinants constitutes a challenge to a number of scholars as it may disclose avenues to temper the difficulties encountered by multitudes of patients, and as it may inform as to the intersection between biology (fundamental mechanisms governing the onset/exacerbation of symptoms), psychology (mental processes occurring in TS patients) and social sciences (development of holistic therapeutic strategies involving patients, family members, care-takers and schoolmates). In this review, we outline some of the core aspects of TS, ranging from its clinical phenomenology, biological and environmental determinants, to the experimental models devised to facilitate its understanding.

\subsection{Tourette syndrome: clinical phenomenology}

TS is a neurodevelopmental disorder characterized by the presence of multiple motor tics and at least one phonic tic throughout a period of more than one year (chronic tics) (Grados and Mathews, 2009). Motor tics usually occur earlier than phonic tics (Leckman et al., 2006). According to the DSM-IV, tic is defined as a "sudden, rapid, recurrent, nonrhythmic, stereotyped motor movement or vocalization" (APA, 2000).

Tic phenomenology is characterized by the repetitive and stereotypic nature of the movements or vocalizations with different degrees of intensity and frequency, and variable durations. Despite their repetitive nature, tics should be kept clearly distinguished from stereotypies (Kurlan, 2010). Several characteristics may help to differentiate them. Compared to tics, stereotypies have an earlier age of onset, are more constant, fixed in their pattern and prolonged in duration. Additionally, tics are generally associated with the need of reducing an inner state of tension (see "premonitory urge") and with a voluntary control over the manifestation of the movement; these features are not present in stereotypies (Singer, 2009).

Early signs of Tourette's usually begin with transient bouts of simple motor tics that generally consist of the movement of the facial and oral musculature; the latter can translate into more complex, elaborate manifestations of the whole body that involve multiple muscle groups (Felling and Singer, 2011). The expression of tics can be preceded by a "premonitory urge", an inner state of discomfort, experienced as irresistible and annoying, often localized in a small area of the body where the tic is about to occur (Bliss, 1980; Bullen and Hemsley, 1983). The need to relieve the sense of distress associated with the urge contributes to give tics a partial characterization of a voluntary act (Leckman et al., 2006; Leckman et al., 1993). Premonitory urges have been proposed to relate to impaired capability of inhibiting responses to irrelevant or inappropriate information (Amitai et al., 2012). This cognitive domain has been studied in TS patients through negative visuospatial priming tasks. These tasks require the subject to respond to a target stimulus during a "probe" trial after a previous exposure to a "prime" trial. Subjects are requested to respond to the presentation of the target stimulus that can be presented in the same or in a different location compared to a previously presented non-target "priming" stimulus ("negative priming"). Normal subjects show a slower response to the target stimulus when this is presented in the same location of the non-target than when it is presented in a different location. TS subjects show a significant impairment in this response (Ozonoff et al., 1998). An additional correlate of premonitory urges that has been shown to be impaired in TS patients is pre-pulse inhibition (PPI), consisting of the inhibition of a startle response following the presentation of a weaker stimulus (Castellanos et al., 1996). Similar to negative priming, PPI entails an appropriate level of attention devoted to a priming stimulus. Experimental procedures for testing "negative priming" and PPI have been developed in humans (Amitai et al., 2012) and translated in rodents (Domeney and Feldon, 1998). Beside being dysfunctional in TS patients and related to premonitory urges, PPI possesses other features particularly relevant to the study of TS. Specifically, it is regulated by the same structures involved in TS pathophysiology (basal ganglia), it is inheritable through genetic mechanisms, and is sensitive to drugs that are frequently used in the treatment of TS, like antipsychotics (Swerdlow, in press). An additional domain, that seems to distinguish TS patients from the normal population is interval timing, i.e. the processing of temporal information (Vicario et al., 2010).

Symptoms have a typical prepubertal age of onset, between 5 and 7 years, with a waxing and waning course, and occur more frequently in males than females, at a ratio of approximately 4:1 (Leckman et al., 2010). Most patients show a gradual increase in tics severity until 8-12 years of age with a marked reduction by the end of adolescence (Lombroso and Scahill, 2008). Although epidemiological studies show that transient tics are quite common in childhood, with up to $20-30 \%$ of children exhibiting brief, repetitive, involuntary movements or sounds (Kurlan et al., 2001), the prevalence of TS is estimated to range between $0.4 \%$ and $1 \%$ in the general pediatric population (Singer, 2005). While particular conditions, such as anxiety, stress, immune reactions and emotional excitement can exacerbate tics, other factors, like those behaviors that involve focusing and attention, can reduce the severity of the symptoms (Leckman et al., 2006; Lin et al., 2007). Specifically, patients 
with Tourette's are able to suppress tics during periods of goaldirected behavior involving motor control, like musical or athletic performances (Leckman et al., 2010). The possibility to inhibit tics under specific conditions constitutes the cornerstone upon which cognitive behavioral therapies (CBT) for tics are designed (Hwang et al., 2012). CBT constitutes one of the most widely accepted therapies for managing tics of a mild to moderate magnitude (Frank and Cavanna, 2012), and is often based on the possibility to replace tics with competitive responses (CR). CRs are enacted upon the appearance of the premonitory urge and should theoretically possess the following characteristics: they should be incompatible with the specific tic (e.g. a slow leftward head movement upon the urge to perform a rapid rightward movement) and less noticeable than the tic itself (Hwang et al., 2012). While a detailed description of the potential treatments for TS falls beyond the scope of this review, we refer the reader to comprehensive reviews regarding the pharmacological (Hartmann and Worbe, 2012) and surgical (Muller-Vahl, in press) approaches for managing tics.

\subsection{Comorbidity: $O C D, A D H D$}

TS is associated with additional neurobehavioral disorders in approximately $80-90 \%$ of patients (Leckman et al., 2010). Affected individuals often develop various comorbid symptoms (e.g. obsessions, compulsions, anxiety, depression, learning problems) (Cavanna et al., 2009; Robertson, 2000), which can be ascribed to other neuropsychiatric pathologies such as attention deficit hyperactivity disorder (ADHD) and obsessive-compulsive disorder (OCD) in $65 \%$ and $30 \%$ of patients respectively (Comings and Comings, 1987; Lombroso and Scahill, 2008). The primary symptom of ADHD is the inability to maintain sustained attention and to exclude irrelevant stimuli. Core futures of the behavior of children with ADHD are impulsivity, emotional liability, motor hyperactivity and distraction (Spencer et al., 2007). OCD begins to manifest in childhood and is characterized by the presence of recurrent and persistent thoughts and impulses that are perceived as intrusive and excessive, followed by repetitive compulsive behaviors (Sheppard et al., 1999). Compulsions (including excessive cleaning, repeating rituals, the need to reorder things) are performed in a stereotyped pattern to reduce the anxiety associated with the obsessions (Miguel et al., 2000). Moreover, OCD is associated with a variety of cognitive deficits, including memory and spatial information processing (Korff and Harvey, 2006), that are also present in patients with TS complicated by co-morbid OCD (Chamberlain et al., 2005). TS and OCD show a similar symptomatology: the repetitive behaviors seem to be involuntary and are exacerbated by stressful situations and emotional events.

Compared to "pure" TS (Denckla, 2006), patients displaying comorbid symptoms are characterized by an earlier onset of tics (Grados and Mathews, 2008). Other conditions that interfere with everyday life, including anxiety disorders, depression, aggressiveness, learning and speech difficulties can also be observed in TS patients (Robertson, 2006b). The close similarity between the progression and the symptomatology of TS, ADHD and OCD may suggest a common pathophysiology. Specifically, it has been hypothesized that a dysfunction in the circuits connecting the basal ganglia to cortical regions may underlie the aforementioned disorders (Gilbert et al., 2004). However, a common etiological cause (genetic or environmental) has not been yet identified.

\section{Neurobiological substrates of tourette}

\subsection{The basal ganglia}

The basal ganglia (BG) comprehend a group of nuclei reciprocally interconnected: the neostriatum (putamen and caudate nuclei), the globus pallidus (subdivided into external -GPe- and internal segment -GPi-), the substantia nigra pars compacta (SNc) and pars reticulata (SNr), and the subthalamic nucleus (STN) (Albin et al., 1989). The striatum receives dopaminergic projections from the SNc and excitatory projections from motor, associative and limbic parts of the cortex and sends inhibitory projections to dorsal thalamic motor nuclei which in turn project to motor cortical areas (Bronfeld and Bar-Gad, 2012). The key to understanding the striatopallidal system is noting two of its basic features. First, many neuronal populations exhibit spontaneous activity, such as the excitatory neurons of the most dorsal thalamic nuclei. In the absence of an inhibitory influence, their outputs result in an increase of the activity, and they thus further stimulate their efferent targets. Second, this system works on the principle of either promoting or inhibiting inhibition. The BG system plays an essential role in the regulation of the cortical excitability and of the selection of movements through its direct pathway (which involves the projections from the neostriatum to GPi to dorsal thalamus) in association with the multisynaptic indirect pathway (from the neostriatum to GPe to STN to GPi) (Felling and Singer, 2011). The first activates motor programs, increasing the probability to initiate movements, while the second indirect pathway is inhibitory and antagonizes the direct pathway.

\subsubsection{Neurotransmitters of the $B G$}

Different neurotransmitters are implicated in the functioning of the $B G$. The main neurotransmitter within the BG is the inhibitory neurotransmitter gamma-aminobutyric acid (GABA), as the projection neurons in the striatum, GPe, GPi, and $\mathrm{SNr}$ are all GABAergic. The striatum also contains cholinergic interneurons which activate GABAergic interneurons. The projections from the cortex, thalamus, and STN are glutamatergic and excitatory (Bronfeld and Bar-Gad, 2012). The activity of the BG is further modulated by dopaminergic inputs from the SNc, which drive the outcome of the striatum and ascending serotoninergic inputs from the dorsal raphe (Leckman et al., 2010). It stimulates the direct loop through its excitatory activity on GABAergic neurons expressing the neuropeptide substance $P$, which in turn act on GPi, thereby favoring movements. Additionally, it inhibits the striatal GABAergic neurons which express the enkephalin leading to the inhibition of the indirect loop.

\subsection{Basal ganglia circuit impairments in TS}

Several studies identified functional and structural dysfunctions of the corticobasal ganglia circuit in patients suffering from TS, OCD, Rett's syndrome and autism spectrum disorder. All these disorders are characterized by the expression of repetitive behaviors (Lewis and Bodfish, 1998; Tanimura et al., 2010). Impairments in the pathways that link the cerebral cortex to subcortical structures, the cortico-striatal-thalamocortical (CSTC) circuits, have been proposed to constitute a common etiological factor potentially explaining the neurobiological relationships between TS and its multiple comorbid problems (Berardelli et al., 2003; Leckman et al., 2010; Singer and Minzer, 2003). Several authors suggested that alterations in the systems belonging to the aforementioned CSTC circuits may be implicated in the onset of the pathology. The involvement of the central dopaminergic system in TS is supported by the fact that dopamine (DA) receptors D2 antagonists reduce tics (Scahill et al., 2006) while D2 receptor agonists increase their frequency (Shprecher and Kurlan, 2009). Moreover, neuroimaging analyses show an excess of nigrostriatal dopaminergic innervation in TS patients (Albin et al., 2003).

A recent postmortem study found a reduction (50-60\%) in the number of two striatal neuronal populations in the brains of TS patients: the fast-spiking GABAergic interneurons, which 
receive inputs from primary motor and somatosensory cortex, and cholinergic neurons which are the target of dopaminergic projections from the SN (Kataoka et al., 2010). This work suggests that a disruption of GABAergic interneurons within the BG could be responsible of an imbalance between the direct versus indirect pathways and may underlie the emergence of motor tics. Earlier studies conducted in animal models already showed the link between the abnormal pattern of activation in the basal ganglia and the appearance of abnormal movements: McKenzie and Viik (1975) demonstrated that the chemical inhibition of striatal GABAergic interneurons in rats induced brief, repetitive, jerk-like movements (McKenzie and Viik, 1975). Similar data have recently been observed in mice: Gittis and colleagues (2011) demonstrated that the selective pharmacological blockade of GABAergic signaling mediated by fast-spiking interneurons within mice striatum is sufficient to induce movement abnormalities resembling human dystonia (Gittis et al., 2011).

Volumetric magnetic resonance imaging studies indicate that TS is also associated with volumetric alterations in CSTC circuits (Peterson et al., 2001). For example, anatomical changes, such as cortical thinning, at the level of the entorhinal, cingulate and orbital frontal cortices have been reported (Muller-Vahl et al., 2009). Morphological abnormalities at the level of sensorimotor cortices have been proposed to hinder the ability to inhibit movements (Sowell et al., 2008). Accordingly, several authors reported a decrease in the volume of the caudate in juvenile and adult TS patients (Kalanithi et al., 2005).

The tight neuroanatomical connection between the limbic system and the basal ganglia has been proposed to underlie the strong correlation between emotional events and the expression of tics (Neuner et al., 2011). This hypothesis is further substantiated by the volumetric changes observed in the hippocampus and amygdala of TS patients (Peterson et al., 2007). The thalamus is considered a relay station between a variety of subcortical regions and the cerebral cortex. Some thalamic nuclei in TS patients show an enlargement in comparison with controls (Miller et al., 2010). The authors hypothesized that this hypertrophy could be considered the consequence of an excess synaptic activity of the motor thalamic nuclei, due to a loss of inhibitory interneurons in the striatum (Ziemann et al., 1997). This hypothesis is not supported by a significant correlation between the degree of the enlargement of the motor thalamic nuclei and the severity of tics. An alternative view may consider the volumetric change as a compensatory mechanism aimed at increasing executive control over dysfunctional motor circuits (Miller et al., 2010; Peterson et al., 2007).

\section{Etiology}

\subsection{Genetic factors}

The discovery of genetic mutations associated with TS supports the hypothesis that the pathology may resemble, under certain circumstances, an autosomal dominant disorder with incomplete penetrance and variable expressivity (Deng et al., 2012). Several approaches are being used to elucidate TS genetic determinants, including candidate gene analysis, genetic linkage, molecular genetic studies and cytogenetics (State, 2011). In the past decades, familial studies showed that the concordance rate of chronic tics in monozygotic twins is $77-94 \%$ and that, compared to the general population, first-degree relatives of affected children have a 10fold to 100-fold increased risk of developing the disorder (O'Rourke et al., 2009). Although these results show a likely genetic origin for TS, the heterogeneity of the symptoms and the presence of frequent comorbidities make the identification of specific genes still ambiguous. Some candidates have been proposed as susceptibility genes, such as inner mitochondrial membrane peptidase 2 like (IMMP2L), contactin-associated protein-like 2 (CNTNAP2), SLIT and NTRK-like 1 (SLITRK1), and neuroligin-4, X-linked (NLGN4X).

The product of the IMMP2L gene is a protein with catalytic activity capable of targeting proteins to the mitochondrial inner membrane. The dysfunctional protein may lead to the activation of the cell apoptotic pathway (Ma et al., 2011), due to a defective mitochondrial function. Such dysfunction has been reported in different neuropsychiatric disorders and could contribute to the symptoms of TS. The disruption of the gene IMMP2L, found in some members of a family with TS, seems to result from cytogenetic abnormalities due to a translocation between the chromosome 7 and 18 (BoghosianSell et al., 1996; Petek et al., 2001). However, the specific role of this gene in the etiology of TS has remained elusive.

Verkerk and collaborators (2003) identified, in a family with TS, a chromosomal translocation involving chromosomes 2 and 7 leading to an interruption in the genomic region containing the CNTNAP2 gene (Verkerk et al., 2003). The latter is a gene encoding a transmembrane protein belonging to the family of the neurexins and is predominantly expressed in the axonal nodes of Ranvier, where it mediates cell-cell interactions. It has been hypothesized that CNTNAP2 may be involved in the positioning of $\mathrm{K}^{+}$voltagegated channels to the juxtaparanode region (Poliak et al., 1999). Its disruption may have an influence on conduction or repolarization of the action potential, leading to an abnormal neural activity in regions involved in the production of tics (Verkerk et al., 2003). Other genes that could be involved in the etiology of pathogenesis of TS are NLGN4X and SLITRK1. The neuroligin- 4 is a transmembrane protein expressed on postsynaptic neurons implicated in synaptogenesis and synapse remodeling (Blasi et al., 2006). The retention of the protein in the endoplasmic reticulum, caused by a mutation that impairs glycosylation processing, could inactivate synapse formation and reduce synaptic strength (Zhang et al., 2009). This type of mutation has been found in members of a family with autism and TS (Lawson-Yuen et al., 2008).

SLITRK1 is a member of a gene family composed of transmembrane proteins with an extracellular domain containing two leucine-rich repeat (LRR) motifs, like the Slit proteins, and an intracellular $C$ terminus that shows similarities to the neurotrophin receptor, the tropomyosin-related kinase (Trk) (Aruga and Mikoshiba, 2003). It is involved in synapse formation and in promoting neuronal survival, neurite outgrowth (Kajiwara et al., 2009) and dendritic branching (Linhoff et al., 2009; Proenca et al., 2011). The profile of expression of Slitrk1 is strictly regionally regulated in the CNS. The discovery that Slitrk1 is expressed in the brain of mice in neuroanatomical regions most commonly implicated in TS (cortex, thalamus and basal ganglia) suggests a possible role of this gene in establishing the corticostriatal circuitry (Stillman et al., 2009). The pattern of expression of Slitrk1 fluctuates during development and is conserved among mammalian species (mouse, rhesus monkey and human). In the cortex, it is expressed in the dendritic branches and then becomes mainly confined to the cell body compartment of pyramidal projection neurons, as the brain matures; in the striatum, Slitrk1 is preferentially associated with neurons of the direct circuit expressing substance $P$ and the dopamine receptor D1, that project to the SN and the GP. These data suggest that SLITRK1 might have a role in the regulation of the nigrostriatal innervation.

Genetic studies have identified several mutations in Slitrk1 gene potentially associated with neuropsychiatric disorders, including TS (Proenca et al., 2011). Among them, an inversion on chromosome 13 , near the region of the gene, has been reported in a patient with TS and ADHD; another mutation in the gene that led to a truncated protein and a missense mutation in the $3^{\prime}$ UTR, that alters the binding of the SLITRK1 protein to the microRNA 189, were reported in other individuals who suffered from TS (Abelson et al., 2005). To clarify the role of the gene in TS, Slitkr1 knockout mice have 
been generated (Katayama et al., 2010). Although these mice did not show the motor impairments characteristic of human TS (see "Transgenic model" section), they had elevated anxiety-like behaviors and increased levels of norepinephrine in the prefrontal cortex, striatum and nucleus accumbens, consistent with the pathology of TS. These heterogeneous findings suggest that mutations in Slitrk1 could have a role in the disease.

In the light of the role played by abnormal basal ganglia related circuits and dopaminergic dysfunctions in TS, recent research has focused on the analysis of genes encoding multiple neurotransmitter systems and their receptors. For example, the finding of a nonsense mutation in the gene L-histidine Decarboxylase (HDC), involved in histamine biosynthesis (Ercan-Sencicek et al., 2010), provided evidence for a role of the histaminergic neurotransmission (involved in maintaining wakefulness and attention) in TS. HDC null mice show decreased histamine and an increased level of stereotypic behaviors upon administration of DA agonists (Cauchi and Tarnok, 2012; Kubota et al., 2002), traits that reflect features of TS.

\subsection{Environmental risk factors}

Several environmental factors including prenatal and perinatal stressors and/or injuries, bacterial and viral infections, have been suggested to contribute to the onset and/or exacerbation of TS (Leckman et al., 1990; Leckman and Peterson, 1993; Leckman et al., 1987). Complications occurring during the prenatal period, including gestational stress, can affect the structural organization of brain networks underlying the symptoms of TS. Motlagh and colleagues (2010) identified different potential prenatal risk factors such as maternal smoking during pregnancy, maternal psychosocial stress, neonatal complications (such as hypoxia) and birth weight (Motlagh et al., 2010). Twin studies suggested that birth weight may correlate with the severity of the symptoms (Hyde et al., 1992; Randolph et al., 1993). Burd and colleagues (1999) identified other potential risk factors, such as paternal age, though in this study birth weight did not emerge as a risk factor (Burd et al., 1999). These factors have been proposed to exert long-term effects whereby they may be implicated in persistent maturational rearrangements. Thus, precocious insults may alter individual development trajectories and ultimately favor the exhibition of TS-associated symptoms.

Beside organizational effects, environmental influences may have short-term consequences on tic expression, whereby they can increase or reduce tic severity. These variables include emotional reactions to specific stimuli (Wood et al., 2003), infections and drugs that can modify tic fluctuations (Conelea and Woods, 2008). For example, while stress, anxiety and frustration are involved in both the maintenance and exacerbation of tics, social interactions and cognitively demanding activities have been shown to reduce tics (Lombroso et al., 1991).

Some clinical studies report that physiological and psychosocial stress can lead to an exacerbation of tics and that stress-related fluctuations in symptoms severity are common (Peterson, 1996). Clinical evidence supports the view that individuals with TS experience more stress than controls and that tic severity may correlate with cortisol levels (Conelea and Woods, 2008). Children with TS show a heightened responsivity of the hypothalamic-pituitaryadrenal (HPA) axis, whereby - compared to control individuals they display higher cortisol levels in response to stress (Corbett et al., 2008). It is not known whether these findings reflect a causal relationship between disturbances in HPA axis activity and TS or whether they are mainly correlational. Some researchers have hypothesized that increased levels of stress-related hormones may influence tic expression through an increase in motor cortex excitability (Rollnik et al., 2000; Swain et al., 2007). In some cases, there is an inverse relationship between cortisol levels and tic severity: in this case, increased expression of tics has been suggested to exert anxiolytic effects, that ultimately reduce cortisol levels (Corbett et al., 2008). In this perspective, according to the model of Evers and Vandewetering (1994), tics may constitute tension-reducing responses (Evers and Vandewetering, 1994). The effects of stressors on tic severity have been suggested to be mediated by the noradrenergic pathway. Specifically, this proposition is supported by the finding that, compared to the normal population, adult TS patients display elevated levels of norepinephrine (NA) in response to stressful events (Chappell et al., 1994). NA may be responsible for the elevation of corticotrophin releasing factor (CRF), released by the hypothalamus, and cortisol found in some TS patients. Other results suggest that, instead of increasing tic frequencies above a baseline level, stressful events may affect motor inhibition processes, controlled by the basal ganglia, reducing individual ability to suppress tics successfully (Conelea et al., 2011).

Additional environmental factors have been proposed and systematically investigated. Specifically, streptococcal infections have been suggested to constitute a likely candidate in the onset of tic disorders. Swedo and collaborators (1998) proposed the acronym PANDAS (pediatric autoimmune neuropsychiatric disorders associated with streptococcal infections) for pathologies characterized by the presence of cross-reactive antibodies induced by group $A$ $\beta$-hemolytic streptococcal (GABHS) infections that bind specifically to BG antigens (Swedo et al., 1998). The proposed criteria for PANDAS are: prepubertal onset, chronic tic disorders or OCD, a relapsing-remitting course, temporal association of onset and one or more exacerbations with Group A Streptococcus (GAS) infection and the presence of a reduced fine motor coordination or increased motor hyperactivity. In support of this hypothesis, different studies (Cardona and Orefici, 2001; Martino et al., 2011; Muller et al., 2001; Rizzo et al., 2006) reported that some patients with TS had previously been exposed to streptococcal infections and/or showed increased anti-basal ganglia antibodies (candidate autoantigens include the lysoganglioside G1 and the dopamine receptors D1 and D2 (Brimberg et al., 2012; Kirvan et al., 2006)).

GAS infection has been shown to relate to the onset or exacerbation of tics in several studies (Dale, 2003; Hoekstra et al., 2002). Several authors proposed that a dysfunctional immune system may constitute a predisposing factor, upon which a subsequent GAS infection may precipitate the abnormal phenotype (Landau et al., 2012; Martino et al., 2009; Murphy et al., 2010). Within this framework, TS patients may have an increased vulnerability towards viral/bacterial infections and/or autoimmune mechanisms which could, in turn, exacerbate the course of the disease. In support of this theory, clinical studies showed the presence of immunological alterations in children with TS: some patients had decreased levels of the immunoglobulins IgA and IgG3 (Bos-Veneman et al., 2011; Kawikova et al., 2010) and a reduced number of T regulatory cells which are important in autoimmunity (Kawikova et al., 2007). Leckman and collaborators (2005) observed increased levels of cytokines, interleukin 12 and tumor necrosis factor alpha (IL12 and TNF- $\alpha$ ) in the serum of TS children during periods of tics exacerbation (Leckman et al., 2005).

Lin and colleagues (2010) investigated the interactive role of GABHS infections and psychosocial stress in the course of TS (Lin et al., 2010): the authors observed that increases in tic and obsessive-compulsive behaviors' severity did not occur after every GABHS infection; yet, these infections resulted in increased expression of tics if associated with concurrent psychosocial stress.

\section{Animal models}

In this section we describe how some of the aforementioned aspects associated with TS (including symptomatology, biological 
predisposition and environmental exacerbating factors) have been translated into preclinical animal models. The latter may inform TS research across several aspects. Specifically, experimental animal models can favor the comprehension of the etiology of pathologies and accelerate the identification of effective treatments (Rickard, 2004; van der Staay, 2006; van der Staay et al., 2009). Animal models aim at replicating the characteristics of pathologies, with respect to the etiology, symptomatology and drugs' efficacy. Such goal can be achieved through diverse paths that may leverage upon unmanipulated individuals spontaneously exhibiting phenotypic abnormalities isomorphic to the pathology, or upon targeted hypothesis-driven manipulations, that ultimately result in experimental subjects exhibiting phenotypic abnormalities analogous to the characteristic symptoms of the pathology of interest. Willner in 1984 proposed three criteria of validity useful to design an animal model relevant to the study of human disorders: face, construct and predictive validity (Willner, 1984). While several authors, added different criteria or edited the original ones (Belzung and Lemoine, 2011) the basic list still constitutes a valuable theoretical and experimental tool.

Willner originally defined face validity as "the extent of similarity between the model and the disorder examined, on as wide as possible a range of symptoms and signs" (Willner and Mitchell, 2002). Indeed, face validity corresponds to the attempt to mimic the behavioral and/or cognitive aspects of the pathological condition, defining a certain "degree of phenomenological similarity between the model and the disorder to be modeled" (Sarter and Bruno, 2002). In brief, an animal model should be isomorphic with the symptomatology expressed in humans to fulfill the criterion of face validity (van der Staay et al., 2009).

Predictive validity is the degree to which the therapeutic effect of specific drugs on animal models correlates with the clinical efficacy of the treatment in humans. Specifically, pharmacological models can be used to detect efficacy of drugs on symptoms and to screen their therapeutic potential. In general, the treatment modalities are expected to be comparable between the animal model and the human patient (Korff and Harvey, 2006). Some authors have extended the significance of this criterion including the ability of the performance of the model to predict some features about the disease (Geyer and Markou, 1995).

Construct validity indicates how closely the model simulates the causes of the disease, based on a current etiologic theory (genetic or environmental). A particular emphasis on construct validity is generally given when aiming at reproducing the symptoms of the pathology (for additional investigations) through the adoption of genetic, surgical or pharmacological interventions at the level of the sites that are thought to be involved in the pathogenesis.

So far, different animal models of TS have been proposed to provide a convergent validation of the clinical aspects previously mentioned. Here we will describe behaviors and neurochemical alterations in mice resembling TS symptomatology, including motor symptoms of the disease, such as motor stereotypies, sequential super-stereotypy, hyperactivity, repetitive grooming, circling and self-injurious behaviors and cortico-striatal circuit dysfunctions. Additionally, we describe experimental models designed in accordance with the current genetic and environmental etiological hypothesis.

\subsection{Experimental paradigms for the analysis of TS and comorbid symptoms (dependent variables)}

Beside tics, TS patients often present a variety of other behavioral abnormalities, including stereotypies, hyperactivity, impulsivity, perseveration, compulsions and self-injurious behaviors, like hair pulling (trichotillomania). Many efforts have been made to identify in animal models abnormal spontaneous behaviors resembling the symptoms of TS. Here we review some of the most suitable.

\subsubsection{Abnormal repetitive behaviors: tics and spontaneous stereotypies}

Phenotypic wise, one of the core limitations of animal models of TS is that only rarely do rodents spontaneously display tics. Tics in mice appear as sudden, out-of-context interruptions of other ongoing activities, such as locomotion or rearing. They are described as very brief jerks and shakes of the head or of parts of the body (Nordstrom and Burton, 2002). Mice seem able to temporarily suppress tics during activities that require attention and concentration, resembling the same ability of TS human patients. The rapid and sporadic nature of spontaneous tics constitutes a substantial experimental hurdle whereby their detection is hard and requests a trained observer. However, pharmacological treatments capable of inducing rapid head twitch responses, highly isomorphic to tics, have been developed (Canal and Morgan, 2012) and hold promise to disclose important avenues in the pre-clinical modeling of TS symptoms (see paragraph "Pharmacological models" for a detailed discussion of these studies). Drug-induced tics are highly predictable and, compared to spontaneous tics, easier to detect (Canal and Morgan, 2012).

Stereotypy is described as a sequence of motor repetitive behaviors that are topographically invariant, rhythmical and apparently purposeless (Dantzer, 1986; Mason, 1991). Several species exhibit spontaneous stereotypic behaviors, sometimes associated with impoverished environmental conditions that often fail to meet animals' ethological needs (Alleva and Vitale, 2000; Branchi and Ricceri, 2004). In the laboratory, rodents housed in standard cages (very simple settings provided with bedding, food and water) can show, even in the absence of pharmacological treatments, repetitive movements, abnormal grooming, bar-mouthing (a series of repetitive functionless sham mouthing movements on a cage bar), aimless locomotion (circling), sequential super-stereotypies and self-injurious behaviors (Powell et al., 1999). The expression and the intensity of these spontaneous self- or cage-directed stereotypies depend on several factors, including housing conditions (individual vs. social housing), age, sex and strain. For example 98\% of ICR (CD1) mice (Wurbel et al., 1996) and approximately $80 \%$ of C57BL/6 mice perform spontaneous stereotypies under standard housing conditions (Garner, 2005).

Motor stereotypies are a common component of several neuropsychiatric disorders and, although they are not equivalent to tics, understanding their fundamental determinants may provide relevant information regarding the neurobiology of TS. It is important to note that stereotypies in laboratory animals can be either stimulated through the administration of psychoactive drugs (pharmacologically-induced stereotypies) or observed in baseline conditions (reflecting captivity-induced stereotypies). Drug-induced and spontaneous stereotypies have been observed in several rodent species including rats (Laviola et al., 2004), mice (Wurbel et al., 1996) and bank voles (Vandebroek et al., 1998). While contemplating the possibility to address stereotypic behaviors as a proxy for TS-like symptoms in rodents, it is necessary to take into consideration that drug-induced and captivity-dependent stereotypies may reflect different mechanisms. While the former may represent a short-term activation of neurotransmitter systems (dopaminergic and serotonergic), the latter may reflect long-term maladaptive processes resulting in an aberrant development of the brain structures responsible for motor behavior. Notwithstanding this caveat, it is important to highlight the fact that both druginduced and spontaneous stereotypies (and tics) are dependent on dysfunctions at the level of the dorsal striatum (Garner and Mason, 2002). The circuitry of the BG represents the "response selection system" which selects the response on the basis of external and 
internal stimuli. Thus, together with stereotypies, a dysfunction in this system may underlie recurrent perseveration (the inappropriate tendency to persist in choosing the same response, irrespective of the outcome) (Garner, 2005). Studies conducted in bank voles (Garner and Mason, 2002) and other animals (Vickery and Mason, 2005a,b) showed that stereotypies correlate with recurrent perseveration in a spatial extinction task and hence with BG system dysfunction. In this paradigm the subject is taught to discriminate between two arms of a maze, one of which is rewarded. During the extinction learning, the animal returns to choose the arm at random because there is no reward. Recurrent perseveration occurs when the animal persists in choosing the response that was previously rewarded. Other studies (Lewis et al., 1990; Martin et al., 1991) conducted in socially deprived non-human primates, also support the association between stereotypies and alterations in cortical BG function. Stereotypy and recurrent perseveration often correlate with high rates of hyperactivity in the animal (Garner and Mason, 2002). These findings do not provide conclusive evidence that all stereotypies are linked to a disruption of the basal ganglia (Gross et al., 2011). However, some lines of evidence may support the hypothesis that some stereotypies are the product of an alteration in brain pathways involving the basal ganglia circuit (Gross et al., 2012).

Some data indicate that the environment (e.g., physical and/or social enrichment) has an important modulatory influence on the amount and type of stereotypies expressed and on their developmental time course (Powell et al., 1999; Turner and Lewis, 2003). While adverse environmental features, such as impoverished environmental settings, maternal deprivation, prolonged individual housing, can cause an animal to develop abnormal repetitive behaviors (Langen et al., 2011), environmental enrichment has been shown to attenuate the development of repetitive behaviors (Muehlmann and Lewis, 2012; Wurbel et al., 1998). Finally, the reduction of stereotypies, dependent on exposure to environmental enrichment, correlates with increased dendritic spine density and neuronal metabolic activity and elevated concentrations of brainderived neurotrophic factor (BDNF) in brain regions associated with cortical basal ganglia circuitry (Lewis, 2004).

\subsubsection{Impulsivity and compulsivity}

The increased expression of impulsive/compulsive behaviors is generally considered, together with stereotypies, a component of the abnormal repetitive behaviors (ARBs) found in animals kept in captivity (Garner, 2005). ARBs involve the variable repetition of an inappropriate goal-directed behavior and they are likely related to the inability of the animal to adapt its behavior to the environmental circumstances (Garner, 2005).

A common form of these repetitive behaviors observed in laboratory mice is barbering, the plucking of fur or whiskers from cagemates or from the animal itself (Long, 1972). Barbering mice may represent a good model for OCD and its related disorders (for example, tic disorders) whereby some phenomenological and etiological characteristics of barbering overlap with trichotillomania (defined as the compulsive urge to remove one's own hair) of human patients (Garner et al., 2004b). The phenomenology of barbering and trichotillomania is similar: hair is removed in repeated patterns from specific body regions (the scalp, the eyebrows and the pubic region) (Reinhardt, 2005). The prevalence of barbering parallels that of trichotillomania in terms of sex bias (females are more likely to barber than males) and age (barbering becomes more common in puberty and sexual maturity). Various etiologic factors have been suggested to underlie them. Just as increased rates of trichotillomania among relatives of patients have been reported, so also a genetic influence has been observed in barbering mice (Garner et al., 2004b; Kurien et al., 2005). Gree and Capecchi described an excessive grooming behavior in Hoxb8 homozygous mutant mice resulting in remarkable hair removal (Greer and Capecchi, 2002). The Hoxb8 gene encodes a nuclear protein which binds DNA sequences, expressed in multiple brain regions including the orbitofrontal cortex and the limbic system (Huber et al., 2012). In the light of their elevated levels of selfgrooming and barbering these mice have been proposed as a potential model for the study of OC-spectrum disorders (Chen et al., 2010). Beside genetic determinants, environmental stressors (e.g. reproductive status) and social factors (e.g. environmental enrichment/impoverishment; presence/absence of social partners) have been proposed to favor barbering. The onset of trichotillomania is also often associated with social stress. Like trichotillomania, barbering seems to be socially facilitated: the presence of a barber in the cage promotes barbering behaviors in cagemates (Garner et al., 2004a).

Other compulsive-like behavioral abnormalities are twitching (the expression of tics), jerking (sudden, spasmodic movements of the head or of parts of the body), repetitive climbing/leaping (jumping) (Swerdlow and Sutherland, 2005). These abnormalities may be screened, in association with stereotypies, as a model of comorbid OCD + TS. These abnormal repetitive behaviors have been proposed to result from anomalous brain development induced by features of the environment or to reflect a deficit at the level of neurochemistry of executive systems, involved in the control of behavior. Different authors (Crider, 1997; Turner, 1997) have proposed that perseveration could be considered the experimental measure of the deficit in behavioral control that underlies the ARBs in human patients. In particular, impulsive/compulsive ARBs have been proposed to correlate with stuck-in-set perseveration, in which a cognitive attentional set is inappropriately repeated while flexible goal-directed responses remain intact (Garner, 2005). This kind of perseverative behavior is thought to be the product of a dysfunction in the "goal selection system" distributed across the prefrontal corticostriatal loop. Some animal models of spontaneous compulsive behaviors show perseverative tendencies: Garner and collaborators (2003) observed that the severity of barbering expressed by laboratory mice correlated with a poor performance on the intra dimensional-extra dimensional (ID/ED) set shifting task (Garner et al., 2003). The latter is the rodent analogous of the Wisconsin-card-sorting task, an experimental paradigm traditionally used in humans to measure the cognitive abilities and the attentional deficits generally associated with prefrontal cortex dysfunction (Birrell and Brown, 2000; Garner et al., 2006). Although TS patients do not exhibit deficits in ID/ED tasks, based on the aforementioned features (correlation with abnormal repetitive behaviors, CSTC-dependent regulation, indicator of abnormal goal selection system) we believe that its use in preclinical models may hold a relevant heuristic value. Although this behavioral task has limited face validity, it can constitute a relevant indirect measurement of TS-related phenotypes.

In this task, subjects must learn a rule to discriminate between different stimuli (such as color, shape, dimension of the objects) and make the right choice in order to obtain a reward (a palatable food pellet); for example, subjects have to learn that a given color (for example, red) is associated with the reward. Once the rule is learnt, the next step is changing the rule: specifically, the reward becomes associated with a different color (intra-dimensional shifting). Following these stages, a previously irrelevant stimulus dimension becomes relevant: for example, the shape of the object becomes the relevant stimulus and the color becomes irrelevant (extradimensional shifting). This task is used in rats and mice to assess the attentional set-shifting abilities and is sensitive to dysfunction at the level of the anterior cingulate cortex and medial prefontal cortex (Tanaka et al., 2011); both these structures show anatomical abnormalities in TS patients (Muller-Vahl et al., 2009). 


\subsubsection{Sensorimotor gating}

One particular feature of TS symptomatology is the sensory experience that precedes the motor or phonic event, known as "premonitory urge". Patients usually become aware of this sensory and mental state some years after the emergence of the tics (Leckman et al., 2006). Premonitory urges are described as sensory and psychic sensations of discomfort that obligate the patients to express the tic to obtain a momentary relief. These personal experiences have been linked to a deficit in a physiological process called "sensorimotor gating" (Castellanos et al., 1996). Healthy people are able to suppress and filter irrelevant sensory, cognitive and motor information to focus attention on appropriate stimuli (Braff et al., 2001). A breakdown in this gating mechanism is thought to be involved in many neuropsychiatric disorders, including schizophrenia, and TS (Quednow, 2008). The loss of sensorimotor gating can be measured in humans, rodents and monkeys through a paradigm called prepulse inhibition (PPI). It is a spontaneous operational measure of physiological processes that correlate with sensorimotor gating, based on the fact that normal individuals show a diminished motor response to a target stimulus (pulse) shortly after the presentation of a stimulus of lower intensity (prepulse), compared with the response to the pulse alone. The motor response is generally represented by the blink reflex in humans and the startle reflex in rodents (Swerdlow and Sutherland, 2005). The startle reflex is a defensive response of the body to a sudden and intense stimulus and, in laboratory animals, it is quantified as the downward force resulting from the contraction of muscles (Swerdlow and Geyer, 1998). PPI has been proposed to serve a protective role, since the consequence of the prepulse is a reduction of motor response to the intense stimulus (Graham, 1975). The study of PPI in TS provides an empirical measure of the deficit in sensorimotor gating represented by premonitory urges. In fact, PPI deficits, described as the inability to inhibit motor responses, should reflect abnormalities in brain circuits that regulate sensorimotor gating. Studies in rats suggest that PPI is regulated by neural pathways that link limbic cortex to the ventral striatum, the ventral pallidum and the pontine tegmentum (Swerdlow et al., 2001). This circuitry provides a descending modulatory input to the nucleus reticularis pontis caudalis in the brainstem which sends projections to motor areas of cranial nerve nuclei and the spinal cord to regulate the startle reflex. Lesions of the ventral and caudodorsal striatum have been reported to decrease PPI in rats (Kodsi and Swerdlow, 1997). Significant deficits in PPI were also identified after $N$-Methyl-D-aspartate (NMDA) lesions of the dorsomedial striatum in C57B1/6J mice (Baldan Ramsey et al., 2011). These findings provide further evidence of the involvement of the CSTC circuitry in the pathogenesis of TS. Druginduced changes in specific brain areas that affect PPI can be used to assess the real contribution of each neural pathway to the emergence of the different pathologies that show PPI deficits. They can also be used to test the therapeutic potential of drugs. For example, dopamine-induced PPI deficits are commonly analyzed for the screening of antipsychotic drugs in animal models (Swerdlow et al., 2006).

\subsection{Experimental models for the induction of TS and comorbid symptoms (independent variables)}

Just as many studies designed experimental paradigms aimed at translating human symptoms into rodent neurobehavioral abnormalities, so also a number of authors developed experimental tools to reproduce, in rodents, TS etiology (construct validity). In the following sections we describe a series of experimental models capable of informing TS etiology from a wide spectrum of convergent perspectives.

\subsubsection{Pharmacological models}

Pharmacological models can be used to predict the effect of putative therapeutic drugs or can be used to induce and/or exacerbate given symptoms. For example, the induction of stereotypies by drugs can provide a direct proof of the contribution of the various components of the basal ganglia in the development of stereotypies. Post-mortem anatomical studies of TS patients identified anatomical brain deficits and hence fostered preclinical studies in which specific brain areas were manipulated through the use of drugs (Felling and Singer, 2011).

The cortico-striatal-thalamocortical circuits contain a series of neurotransmitters, neuromodulators and neuropeptides that can be remarkably influenced by the administration of different classes of psychoactive compounds. Within this framework, the dopaminergic system was the first to be associated with repetitive behaviors, whereby, according to the "dopamine hypothesis" for TS, an excess of nigrostriatal dopaminergic activity may alter the balance between the direct and the indirect pathway (Singer et al., 1982). Dopaminergic drugs that stimulate the direct excitatory loop (activating D1 receptors in the neostriatum) provide a positive feedback to the motor cortex (Langen et al., 2011). The use of dopamine D2 agonists, such as apomorphine, induce a disinhibition in the dorsal basal ganglia that culminate in stereotypy (Leckman et al., 2010); while dopaminergic antagonists, such as haloperidol, acting on D2 receptors, induce tic suppression (Scahill et al., 2006). The tic severity correlates with an increased sensitivity of D2 receptors and a higher density of DA transporters (DAT) (Cheon et al., 2004) (responsible for the re-uptake of DA from the synaptic cleft) in the caudate and putamen areas (Muehlmann and Lewis, 2012). An increase in tic frequency has also been reported following the exposure to agents that indirectly increase central dopaminergic activity such as L-dopa (Gilbert et al., 2003).

A recent study in animal models (Li et al., 2010) provided further evidence of a possible role of both DA and serotonin (5-HT) in the pathophysiology of TS. The authors developed an experimental model of TS by microinfusing sera from TS patients (thought to be rich in antineural antibodies; see also below the section on autoimmune models) directly into the ventral striatum of rats. A higher DA content and lower levels of 5-HT were observed in striatum homogenate of TS rats compared to the control group. The abnormalities in the concentration of DA and 5-HT could be explained by a dysfunction in the expression of DA and 5-HT transporters: the analysis of protein and mRNA levels revealed a reduction in the expression of DAT and an increased expression of serotonin transporter (SERT). These results in the animal model confirm the importance of DA in the pathophysiology of TS and also suggest a possible role for 5-HT.

Following GABAergic drugs administration directly in selected brain regions, different behavioral effects have also been observed. Administration of GABA agonists in rats into the $\mathrm{SNr}$ (Scheel-Kruger et al., 1977) and into the frontal cortex (Karler et al., 1998), respectively, exacerbates or attenuates stereotypic behaviors. In humans, benzodiazepines, acting on GABA receptors, have been shown to induce tic suppression (Gonce and Barbeau, 1977).

The balance of activity between glutamatergic projection pathways and GABAergic neurons appears to be a key factor in the emergence of tics (Leckman et al., 2006). Indeed, the use of glutamate receptor agonists in rodents can induce stereotypies (Langen et al., 2011).

An additional pharmacological treatment potentially capable of informing TS research is constituted by the administration of hallucinogenic 5- $\mathrm{HT}_{2}$ receptor agonists, such as 2,5-dimethoxy4-iodoamphetamine (DOI) and psilocin (Canal and Morgan, 2012; Halberstadt et al., 2011). The administration of these substances to rats and mice readily induces head twitch response (HTR) behavior. The latter has a great degree of face validity with human tics 
whereby it consists of an easily detectable, rapid and violent head shaking that generally does not occur in normal mice. Beside face validity, hallucinogenic-induced HTR possess an elevated degree of predictive validity in the field of TS as they can be mitigated through the administration of dopamine $\mathrm{D}_{2}$ antagonists like haloperidol and chlorpromazine (see (Canal and Morgan, 2012) for a detailed discussion of the utility of the HTR model in rodents). We offer that this model can be of relevance while investigating novel therapeutic approaches: specifically, it can serve the aim of testing novel treatments selectively targeting 5 -HT receptors.

\subsubsection{Genetic models}

The role of specific genes, among those identified in epidemiological analysis, has been also investigated by means of engineered animal models (Cauchi and Tarnok, 2012). According to the hypothesis that a genetic event can trigger a dysfunction in brain circuits implicated in TS, rodent models bearing different gene mutations have been developed.

The identification of mutations in the gene encoding the SLITRK1 paved the way to the development of Slitrk1 knockout (ko) mice (Katayama et al., 2010). We believe that this model has a major advantage and several limitations. With respect to the former, we note that it has been developed in accordance with a clear genetic hypothesis, derived from clinical data. Within this framework, we believe that this model possesses a great degree of construct validity. However, the phenotype of Slitrk1-ko mice does not adequately resemble TS symptoms, as these mice do not show any impairment in tic-like symptoms and behavioral stereotypies. Additionally, Slitrk1-ko mice do not display any neuroanatomical and phenotypic abnormality, except that the null homozygotes are most likely to die before weaning and that males have a reduced body weight. The behavioral analysis showed that Slitrk1-deficient mice have a general reduction in locomotor activity and are characterized by increased anxiety-like behaviors in the elevated plus maze. Specifically, Slitrk1-deficient mice exhibited significant decrease in entries and in the percentage of time spent into the open arms compared to wild type animals. Their anxiety-related profile was also attenuated by the administration of clonidine, an alpha 2-adrenergic agonist. The latter is used in the treatment of TS (Robertson, 2006a). The authors also noted that mutant mice showed an increased immobility time in the tail suspension test and in the forced swimming test. Neurochemical analyses showed that the level of NA and its metabolite MHPG tended to be elevated in the prefrontal cortex, striatum and nucleus accumbens of transgenic mice, suggesting an altered status of NA neurotransmission which, according to clinical evidence, is associated with stress and anxiety (Bremner et al., 1996). An unexpected result was that Slitrk1-null mice did not exhibit any abnormal repetitive or compulsive and tic-related behavior.

A high degree of face validity has been reached with the transgenic mouse model proposed by Nordstrom and colleagues (Campbell et al., 1999; Nordstrom and Burton, 2002). These authors developed a D1 receptor (D1CT-7) transgenic mouse model which expressed two hyperactive groups of neuronal populations in the adult CNS. The first subset of neurons were the glutamatergic pyramidal neurons expressing D1 and 5-HT2 receptors, located in insular and piriform cortices, which send excitatory projections to sensorimotor, orbitofrontal and corticostriatal areas; the second subset were the D1 + GABAergic interneurons of the intercalated nucleus of the amygdala. The D1CT-7 mouse model is based on the construct that TS is linked to the glutamatergic hyperactivity within the cortical, limbic and cortico-striatal circuitry. These mice express repeated biting and skin pulling of cagemates during grooming, representing a good model for OCD, but they also exhibited comorbid TS-like behaviors, including tics, defined as any very brief (0.05-0.1 s) isolated head and body jerk or shake. D1CT-7 mice show features that are similar to the tics phenomenology of TS patients. Mutant mice twitch more frequently than control mice, with male mice showing more severe tics than female mice. Furthermore, the incidence of complex tics (multiple types of head and body shakes) is greater than simple motor tics and the onset of tics begins in mice at juvenile age. The predictive validity (see above) of this model is supported by the fact that the tics are reduced by the administration of the alpha 2 agonist clonidine which, acting on presynaptic norepinephrine targets in limbic and cortical areas, is thought to reduce excitatory output to the striatum. Notably, the drug has the same effect in the alleviation of tics in humans (Leckman et al., 1991). This model represents a good prototype for models that mimic the neuronal abnormalities of TS, even though it exhibits a number of features that are not characteristic of TS patients (a reduced seizure threshold and sensitivity to NMDA antagonists). It is unknown whether D1CT-7 mice also share the exaggerated rigid and serially-complex sequence of compulsive behaviors that often occur in TS and OCD patients.

The normal sequential pattern of actions has been suggested to depend on the integrity of basal ganglia. Rats with lesions of neostriatum and disruption of DA neurotransmission lose the ability to complete the entire sequence of an action (Aldridge et al., 2004; Cromwell and Berridge, 1996). A mutant mouse model of hyperdopaminergic activation (DAT-kd) has been developed (Zhuang et al., 2001) and tested for sequential super-stereotypy (Berridge et al., 2005). These mice present a genetic knockdown of the DAT resulting in a decreased synaptic re-uptake of DA and hence elevated levels of extracellular DA in the neostriatum. Mutant mice tend to be hyperactive, to walk in perseverative straight paths and to show excessive body grooming. In general the evidence described above indicates that hyperdopaminergic mice exhibit marked increments of spontaneous stereotypies and rigid manifestations of complex fixed action patterns, in particular grooming behavior (Berridge et al., 2005). It is possible that in DAT-kd mice a basal increased activation of D1 receptors may be responsible for the perseveration and sequential rigidity in behavior (Cromwell et al., 1998). L-histidine Decarboxylase (HDC) knockout mice constitute an additional relevant research avenue: these mice are considered a model for the HDC-mediated predisposition towards TS. Beside displaying receptor abnormalities at the level of the dopaminergic system, these mice show an impairment in PPI (see (Swerdlow, in press) for a discussion).

\subsubsection{Environmental models and early risk factors}

Neurological models of TS suggest that tic variability, observed during the course of the pathology, may be the result of altered neural activity in the cortico-striatal pathway. These alterations have been put in relation with mutations of specific genes (innate genetic vulnerability) affecting the regular development of brain circuits or with environmental factors that, especially during critical periods of brain maturation, exert a major impact on brain organization and functioning. Genetic predispositions in association with environmental contribution may favor the emergence or exacerbation of neurobehavioral dysfunctions, including neuropsychiatric diseases. Rodent models resting upon the administration of different stressors or insults during highly plastic developmental stages (prenatal period, early infancy and adolescence) disclosed important avenues in the analysis of the environmental determinants of altered developmental trajectories leading to psychiatric disturbances (Marco et al., 2011).

For example, severe obstetric complications, including perinatal hypoxia (which appears to be a risk factor for the development of TS), in rats produce short- and long- term changes in metabolism of several neurotransmitter systems, mainly acting at the level of the nigrostriatal pathway, indicating a permanent deficit in the functioning of the basal ganglia (Chen et al., 1997). Laboratory 
rats exposed to neonatal asphyxia exhibit alterations in quality of social interactions, increased level of neophobia and behavioral stereotypies (symptoms also found in schizophrenia and autism) in response to amphetamine (Laviola et al., 2004). Amphetamine is known to induce a release of DA in the striatum which, in turn, may be responsible for increased compulsive and stereotyped behaviors (Dantzer, 1986). Reduced levels of BDNF have also been observed in the striatum of rats exposed to neonatal asphyxia: BDNF has been proposed to exert a neuroprotective role whereby it increases the survival of DA neurons (Dluzen et al., 2002). Its reduction may relate to variations in the functionality of the DA system, ultimately increasing the likelihood to display abnormal reactions to social and environmental novelty (Laviola et al., 2004).

Clinical observations support an association between maternal stress during pregnancy and increased risk for the offspring to develop tic-related disorders. Several experimental studies investigated the consequences of prenatal stress in laboratory rodents. Maternal exposure, during pregnancy, to stressful environmental challenges (for example, restraint stress) has been shown to result in rats exhibiting a reduction in social play behavior during adolescence (Laviola et al., 2004; Morley-Fletcher et al., 2003) and an increase in anxiety-like behaviors (Kohman et al., 2008; Laviola et al., 2004). Rats born to stressed dams also display impaired ability in spatial learning and attentional deficits (Lemaire et al., 2000). Prenatal restraint stress is also responsible for a long-lasting hyper-activation of the HPA axis, involved in the regulation of physiological functions, growth and reproduction, in adult subjects (Maccari and Morley-Fletcher, 2007). Prenatally stressed rats exhibit, when adults, significant elevation of CRF (one of the main actors of the HPA axis) in the amygdala, in response to stressful stimulation (Kay et al., 1998). This indicates a hyperactivity of the HPA axis. CRF released from the hypothalamus is believed to play an important, evolutionary conserved role in modulating central neural activity and stress-related behaviors. In response to external threat, it seems to induce in rodents an increase in locomotion in a familiar environment, through complex interactions with serotoninergic and dopaminergic pathways in specific brain regions (Carpenter et al., 2007). Stress during gestation has also been associated with negative consequences at the level of the immune system, increasing the risk of infections during postnatal life. Adult rats with a history of severe stress during gestation show a significant reduction in CD4T and CD8T lymphocytes and circulating anti-inflammatory IL-10 cytokine and a significant increase in proinflammatory cytokine IL-1 $\beta$ (Laviola et al., 2004). The alterations in the immune system in interaction with changes of neuroendocrine system function may relate to the emergence of neurological diseases (Dantzer and Kelley, 1989). Hormones such as CRF, cortisol and catecholamines, related to the physiological stress-response system, acting on receptors located on mediators of the immune system, such as lymphocytes and monocytes, may modulate an perhaps compromise immune function, thus possibly altering the course of immune-related diseases (Marshall and Agarwal, 2000). Stress hormones can affect disease susceptibility and the outcome of various immune-mediated diseases (autoimmunity, infections and neurological/psychiatric disorders) by acting through a dysregulation of the pro vs. anti-inflammatory factors (IL-12, TNF $\alpha$, IL-10, TGF $\beta$ ) balance (Calcagni and Elenkov, 2006).

A number of studies also suggest that immune, metabolic and neurobehavioral dysfunctions can be reversed by the exposure of rodents to an enriched (in its physical and/or social components) environment ( $\mathrm{Li}$ et al., 2012). Thus, the environment can exert its influence on multiple plastic stages of brain development. In preclinical literature, environmental enrichment refers to housing conditions in which sensory, cognitive, motor and social stimulations are enhanced. The experience of enriched living has been associated in rodents with increased release of neurotrophins as well as with improved neurogenesis in dentate gyrus in adult brains (Laviola et al., 2008). The neuroprotective role of environmental enrichment has been observed in several animal models for Alzheimer's disease, Parkinson's disease and other brain damages (Jeong et al., 2011; Schilling et al., 2004; Stewart et al., 2012). Morley-Fletcher and colleagues (Morley-Fletcher et al., 2003) demonstrated that the exposure to environmental enrichment of adolescent rats subjected to severe stress during gestation rescued the animal performance in social behavior and markedly reduced the activation of the HPA axis in response to adult stress. Enriched living was also shown to completely revert the immunological alterations produced by a stressed pregnancy (Laviola et al., 2004).

\subsubsection{Immune-mediated models}

As already discussed above, several studies propose a link between immune-mediated alterations in basal ganglia and TS symptoms (Landau et al., 2012; Martino et al., 2009; Martino et al., 2008; Morer et al., 2008; Muller et al., 2000). Specifically, epidemiological studies observed the existence of a relationship between GABHS infections and the presence of anti-basal ganglia antibodies in TS patients (Cardona and Orefici, 2001; Martino et al., 2011; Muller et al., 2001; Muller et al., 2000; Rizzo et al., 2006). Beside TS, the presence of autoimmune responses directed towards specific brain targets has been observed in several pathologies (such as CNS vasculitis, encephalomyelitis, type 1 diabetes mellitus, lamberteaton myasthenic syndrome, myasthenia gravis, multiple sclerosis) (Davison, 2012). Within this framework, some animal models, addressing the link between circulating natural auto-antibodies (aAbs) and disease-like neurobehavioral abnormalities have been developed (see (Hornig and Lipkin, 2013) for a detailed review). We recently identified a change in the level of natural antibodies against SERT and DAT proteins in serum samples of mice exposed, during the neonatal period, to stress-related conditions, here mimicked by different dosages of corticosterone (Macrì et al., 2009). We also reported, using a different approach, that the immunization with GluR1 peptide fragments (a subunit of the AMPA receptor) which are thought to act as antigens and trigger an autoimmune response in CD1 mice was associated with significant increment in circulating GluR1 aAbs. These immunized mice are hyperactive and show a marked elevation of self grooming activity when exposed to an unfamiliar cage, suggesting a marked stress-elicited activation of the dopaminergic system (Capone et al., 2008). Finally, we recently observed that immunization with dopamine transporter fragments resulted in persistent long-term adjustments in mice. Specifically, immunized mice displayed an elevation in circulating autoantibodies to dopamine transporters, spontaneous hyperactivity, and reduced cognitive flexibility and impulse control. Finally, immunization resulted in persistent variations in striatal concentrations of dopamine and its metabolites (Adriani et al., 2012).

It has been proposed that the reaction of GABHS IgG against basal ganglia neurons might be one of the possible environmental factors responsible for the symptoms related to PANDAS, including TS. Recently, animal models of immune-mediated TS have been developed. Studies in rats reported that passive transfer of sera from individuals with TS, with high levels of antineural antibodies, directly into the striatum produced a significant increase in stereotypic behaviors (Hallett et al., 2000; Taylor et al., 2002). One proposed mechanism for serum-induced stereotypies is that IgG recognize specific neuronal antigens within the striatum and interfere with its normal functioning.

Using a different approach (active immunization), other studies showed that basal ganglia dysfunctions may be triggered in vulnerable individuals by GABHS (Swerdlow and Sutherland, 2005). For example, female mice (SJL/J strain) actively immunized with GABHS exhibited some behavioral abnormalities (motor hyperactivity and stereotypes), that satisfy some of the criteria for PANDAS: thus, 
Table 1

Synopsis of the validity of animal models relevant to Tourette Syndrome.

\begin{tabular}{|c|c|c|c|c|c|}
\hline & Model & $\begin{array}{l}\text { Face } \\
\text { validity }\end{array}$ & $\begin{array}{l}\text { Construct } \\
\text { validity }\end{array}$ & $\begin{array}{l}\text { Predictive } \\
\text { validity }\end{array}$ & Major limitations \\
\hline \multirow[t]{4}{*}{ Genetic models } & $\begin{array}{l}\text { Slitrk1 KO mice (Katayama et al., 2010; Robertson, } \\
\text { 2006a) }\end{array}$ & - & + & + & Limited symptoms' similarity \\
\hline & $\begin{array}{l}\text { D1CT-7 transgenic mice (Campbell et al., 1999; } \\
\text { Nordstrom and Burton, 2002) }\end{array}$ & +++ & ++ & ++ & $\begin{array}{l}\text { Exhibition of additional features not } \\
\text { characteristic of TS }\end{array}$ \\
\hline & DAT-KD mice (Zhuang et al., 2001) & + & ++ & NA & It does not exhibit twitching behaviors \\
\hline & HDC null mice (Kubota et al., 2002) & + & + & NA & It does not exhibit twitching behaviors \\
\hline \multirow[t]{2}{*}{ Environmental models } & $\begin{array}{l}\text { Prenatal stress } \\
\text { (see paragraph } 4.2 .3 \text { in the text) }\end{array}$ & - & + & NA & Genetic component absent; \\
\hline & $\begin{array}{l}\text { Perinatal hypoxia } \\
\text { (Chen et al., 1997) }\end{array}$ & NA & + & NA & Limited symptoms' similarity \\
\hline \multirow[t]{2}{*}{ Pharmacological models } & $\begin{array}{l}\text { Serotoninergic agonists } \\
\text { (Canal and Morgan, 2012) }\end{array}$ & +++ & + & ++ & $\begin{array}{l}\text { Only specific receptors are targeted; } \\
\text { Induction of stereotypies (not tics) }\end{array}$ \\
\hline & $\begin{array}{l}\text { Dopaminergic agonists } \\
\text { (Leckman et al., 2010) }\end{array}$ & ++ & + & ++ & \\
\hline Immune-mediated models & $\begin{array}{l}\text { Brimberg et al., 2012; Hallett et at, 2000; Hornig and } \\
\text { Lipkin, 2013; Swerdlow and Sutherland, } 2005\end{array}$ & + & + & + & Genetic component absent \\
\hline
\end{tabular}

Note: variable degrees of validity for each animal model are indicated with-and + symbols; NA= not allowed.

immunized mice developed antibodies directed against streptococcus $M$ protein, but these antibodies further cross-reacted against mouse cerebellum, globus pallidus and thalamus (Hoffman et al., 2004). GABHS mice, like PANDAS children, present a spectrum of abnormalities characterized by complex behavioral problems and elevated antibody titers that bind to CNS targets (hippocampal dentate gyrus granule cells and cells of the caudate nucleus). An analogous symptoms' profile has been obtained in naïve male mice after passive transfer of serum from GABHS donor mice (Yaddanapudi et al., 2010). In contrast, the observation that IgGdepleted GABHS sera did not produce the same effect, indicates that IgG is the active, key component in the induction of behavioral abnormalities (Yaddanapudi et al., 2010). Both GABHS donor mice and passive transfer mice show repetitive behaviors and deficits in motor coordination (reminiscent of human tics and compulsions). This study supports the hypothesis that some neuropsychiatric disorders (including TS) may be triggered by a direct action of GABHS-associated antibodies on brain structures. A recent model similarly demonstrated that the exposure of male Lewis rats to GAS antigens leads to motor impairments related to symptoms of PANDAS that were attenuated by the administration of haloperidol and paroxetine, which are used to treat motor disorders in PANDAS cases (Brimberg et al., 2012). This study supports a causal relationship between exposure to GAS and the development of anti-brain antibodies and is the first to reveal the presence of autoantibodies against D1 and D2 receptors in the sera of immunized rats. Indeed, the evidence suggests a role for dopaminergic alterations induced by an autoimmune reaction in the emergence of symptoms related to PANDAS, including TS.

\subsection{Concluding considerations regarding the use of rodent models of TS}

The multifaceted nature of the rodent models described in the previous sections (symptom- and etiology-wise) reflects the diverse perspectives from which TS can be analyzed. Specifically, preclinical studies can serve the aim of testing pathogenic hypotheses and/or the therapeutic potentials of given strategies. Within this broad framework it would be difficult to prioritize the quality of the models hitherto described. However, it is possible to classify these models with respect to the validity criteria discussed above. Specifically, we believe that each of the models described in the previous sections may provide relevant information to the study of TS. Yet, such relevance should be framed within the specific hypotheses to be tested. In Table 1, we report a brief synopsis of the preclinical models of TS alongside their face, construct and predictive validity. The main limitation of this table is that validity criteria have been arbitrarily estimated. Rather than representing a ranking, we believe that such table may constitute a theoretical tool against which evaluating preclinical models in general. With respect to the specific aspects of this review, we note that none of the models designed ranks highest on each of the validity criteria. Additionally, while all the preclinical models described possess variable degrees of validity, none of them encapsulates all the information that has been derived from clinical studies. Etiology-wise, several models contemplated either genetic predispositions or environmental factors; yet, none of them apparently designed a rodent model in which gene $\mathrm{x}$ environment interactions have been combined. Symptom-wise, spontaneous tic-like behaviors have been successfully matched to a clear genetic pathogenic prediction only in Nordstrom and Burton (2002). Pharmacological treatments, resting upon 5-HT agonists, appear particularly promising in inducing tic-like behaviors and in offering a tool against which testing the therapeutic potentials of drug targets. Additionally, autoimmune models (e.g. (Hoffman et al., 2004; Yaddanapudi et al., 2010)) appear particularly promising in testing the possibility that TS may fall within the definition of PANDAS. Thus, each model can target specific aspects of the disease. However, current models do not seem capable of incorporating all the aspects of TS.

Therefore, we believe that future efforts should aim at combining some of the aforementioned models such as to account for the gene $x$ environment pathogenic hypothesis of TS. To this aim, several pathogenic predictions and appropriate research strategies should be considered. Genetic predispositions shall be addressed either through mouse engineering or through classical strain differences studies; environmental vulnerability factors shall subsequently be combined and adopted in the previously-selected genetic vulnerability model. Additionally, the behavioral phenotyping of these models should contemplate all the variables that directly or indirectly can be ascribed to tics and to their underlying neural mechanisms.

\section{A unifying perspective bridging clinical and pre-clinical evidence in TS}

In the present manuscript we aimed at describing the symptomatology and etiology of TS and at identifying appropriate pre-clinical models allowing the possibility to test evidence-driven 


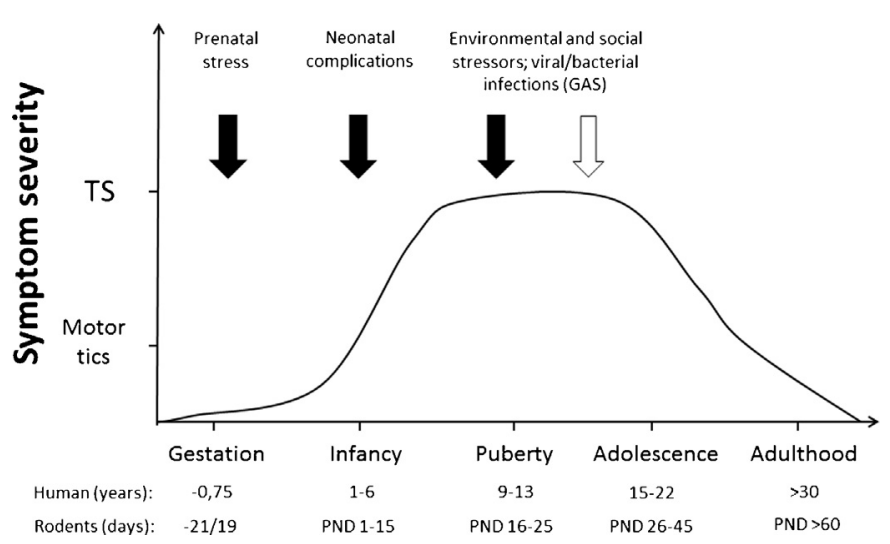

Fig. 1. Graphical representation of the main concepts expressed in the present review. We describe the environmental variables influencing the onset and course of TS symptoms in humans and animal models. On the $y$-axis we report the gravity of symptoms (from low, no symptoms, to peak, full-blown pathology). The arrows indicate the potential vulnerability factors as observed both in clinical and preclinical studies. Black arrows indicate vulnerability factors exerting organizational effects (delayed consequences) while the white arrow indicates factors exerting activational effects (immediate consequences). The $\mathrm{x}$-axis reports the different maturational stages and the age at which these stages are approximately attained in humans (years) and rodents (postnatal days, PND). See text for additional details.

hypotheses and generate novel predictions. The core aspects of the present review are summarized in the unifying model sketched in Fig. 1. Specifically, the model incorporates a series of data indicating that environmental insults, occurring during specific life stages, may favor the onset and exacerbate the course of TS symptoms. In the model proposed in Fig. 1, symptoms are reported on the $y$-axis whereby low values correspond to the absence of symptoms and peak values to the presence of a full-blown syndrome. The $x$-axis accounts for individual development and for the possibility that environmental insults occurring at different maturational stages may further increase the likelihood to develop TS (e.g. difficult pregnancy, maternal smoking, GABHS infection, psychosocial stressors). Additionally, the graph accounts for the typical sinusoidal course of TS. Specifically, as also noted in the previous paragraphs, TS symptoms' gravity generally escalates during infancy/childhood and declines throughout adolescence.

A key aspect that warrants further discussion and that has not been thoroughly described in the present manuscript relates to the development of the basal ganglia circuit. Specifically, an aberrant regulation of this circuit has been proposed to underline the inability to control spontaneous movements thereby representing the neural correlate of tics (see above). It is thus tenable to propose that symptoms' onset and exacerbation depend on an abnormal developmental regulation of the basal ganglia and that remission may be related to some form of compensatory growth occurring in adolescence. To investigate the potential alterations in basal ganglia developmental trajectories, it would be necessary to first describe normal development and then evaluate whether TS patients deflect from such norm. Marsh and colleagues (Marsh et al., 2009) addressed this issue through a systematic analysis combining neuroimaging information describing normative development of the basal ganglia, and neuropsychological (Stroop test) evaluation of self-regulatory control in normal individuals and TS patients. Although preliminary, these studies suggest that the basal ganglia and neuropsychological performance steadily mature throughout childhood reaching adult levels not earlier than around 12 years of age. Indirect evidence, emerging from systematic literature reviews, suggests that such normative development may be altered in TS patients (Marsh et al., 2009). Future studies are needed to clarify whether maturational asynchronies may explain the observation of tics in patients.
The graph reported in Figure 1 is meant to apply to both clinical and preclinical studies. Thus, vulnerability factors (arrows) reflect clinical studies in the human population and experimental procedures - aimed at reproducing the same variables - in animal models. Genetic vulnerability, which for the sake of clarity has not been reported in the figure, can be achieved, in animal models, through spontaneous mutations or mouse engineering.

The parallelism between clinical and preclinical studies is also strengthened in the x-axis, wherein we approximately align human and rodent ages (in years and days, respectively) at given developmental stages. The strict comparison between clinical and preclinical studies also serves the aim of highlighting the perspectives and limitations of the different methodologies adopted. Thus, animal models appear a fundamental tool to test evidencedriven hypotheses under entirely controllable conditions. These models also offer the possibility to investigate pathology-induced modifications potentially constituting novel biological markers of disease. Within this perspective, they can complement clinical studies whenever the latter may be hindered by reduced patient availability or obvious ethical concerns. Yet, animal models are also limited by a series of fundamental shortcomings. Among the several limitations of animal models, we give a particular emphasis to the timing of the onset of TS-like symptoms in rodents. Specifically, in spite of the fact that TS is predominantly a pediatric disease, most of the symptoms (tics, stereotypies and sensory-motor gating deficits) have not been modeled yet in developing animals, but rather in adolescent/adult rodents. Thus, future studies with a specific ontogenetic focus are needed to identify earlier TS-like neurobehavioral and immunological markers in rodents.

Ultimately, we believe that a continuous dialogue between complementary disciplines is needed in order to inform as to future research avenues and novel therapeutic strategies in TS.

\section{Acknowledgements}

The authors of this manuscript received funding from the European Community's Seventh Framework Programme (FP7/2007-2013) under grant agreement no. 278367. This paper reflects only the authors' views and the European Union is not liable for any use that may be made of the information contained therein.

\section{References}

Abelson, J.F., Kwan, K.Y., O‘Roak, B.J., Baek, D.Y., Stillman, A.A., Morgan, T.M., Mathews, C.A., Pauls, D.A., Rasin, M.R., Gunel, M., Davis, N.R., Ercan-Sencicek, A.G., Guez, D.H., Spertus, J.A., Leckman, J.F., Dure, L.S., Kurlan, R., Singer, H.S., Gilbert D.L., Farhi, A., Louvi, A., Lifton, R.P., Sestan, N., State, M.W., 2005. Sequence variants in SLITRK1 are associated with Tourette's syndrome. Science 310, 317-320.

Adriani, W., Koot, S., Columba-Cabezas, S., Romano, E., Travaglini, D., van den Bos, R., Granstrem, O., Ali, S., Laviola, G., 2012. Immunization with DAT fragments is associated with long-term striatal impairment, hyperactivity and reduced cognitive flexibility in mice. Behavioral and Brain Functions, 8.

Albin, R.L., Koeppe, R.A., Bohnen, N.I., Nichols, T.E., Meyer, P., Wernette, K, Minoshima, S., Kilbourn, M.R., Frey, K.A., 2003. Increased ventral striatal monoaminergic innervation in Tourette syndrome. Neurology 61, 310-315.

Albin, R.L., Young, A.B., Penney, J.B., 1989. The functional anatomy of basal ganglia disorders. Trends Neurosci. 12, 366-375.

Aldridge, J.W., Berridge, K.C., Rosen, A.R., 2004. Basal ganglia neural mechanisms of natural movement sequences. Can. J. Physiol. Pharmacol. 82, 732-739.

Alleva, E., Vitale, A., 2000. We urgently need more data to improve the lives of laboratory animals. Nature 405, 116.

Amitai, N., Weber, M., Swerdlow, N.R., Sharp, R.F., Breier, M.R., Halberstadt, A.L., Young, J.W., 2012. A novel visuospatial priming task for rats with relevance to Tourette syndrome and modulation of dopamine levels. Neurosci. Biobehav. Rev..

Aruga, J., Mikoshiba, K., 2003. Identification and characterization of Slitrk, a novel neuronal transmembrane protein family controlling neurite outgrowth. Mol. Cell. Neurosci. 24, 117-129.

Baldan Ramsey, L.C., Xu, M., Wood, N., Pittenger, C., 2011. Lesions of the dorsomedial striatum disrupt prepulse inhibition. Neuroscience 180, 222-228.

Belzung, C., Lemoine, M., 2011. Criteria of validity for animal models of psychiatric disorders: focus on anxiety disorders and depression. Biol. Mood Anxiety Disord., 1. 
Berardelli, A., Curra, A., Fabbrini, G., Gilio, F., Manfredi, M., 2003. Pathophysiology of tics and Tourette syndrome. J. Neurol. 250, 781-787.

Berridge, K.C., Aldridge, J.W., Houchard, K.R., Zhuang, X., 2005. Sequential superstereotypy of an instinctive fixed action pattern in hyper-dopaminergic mutant mice: a model of obsessive compulsive disorder and Tourette's. BMC Biol. 3, 4 .

Birrell, J.M., Brown, V.J., 2000. Medial frontal cortex mediates perceptual attentional set shifting in the rat. J. Neurosci. 20, 4320-4324.

Blasi, F., Bacchelli, E., Pesaresi, G., Carone, S., Bailey, A.J., Maestrini, E., Int Molecular Genetic Study, A, 2006. Absence of coding mutations in the X-linked genes neuroligin 3 and neuroligin 4 in individuals with autism from the IMGSAC collection. Am. J. Med. Genet. Part B-Neuropsych. Genet. 141B, 220-221.

Bliss, J., 1980. Sensory experiences of Gilles de la Tourette syndrome. Arch. Gen. Psych. 37, 1343-1347.

BoghosianSell, L., Comings, D.E., Overhauser, J., 1996. Tourette syndrome in a pedigree with a 7;18 translocation: Identification of a YAC spanning the translocation breakpoint at 18q22.3. Am. J. Hum. Genet. 59, 999-1005.

Bos-Veneman, N.G.P., Olieman, R., Tobiasova, Z., Hoekstra, P.J., Katsovich, L., Bothwell, A.L.M., Leckman, J.F., Kawikova, I., 2011. Altered immunoglobulin profiles in children with Tourette syndrome. Brain Behav. Immun. 25, 532-538.

Braff, D.L., Geyer, M.A., Swerdlow, N.R., 2001. Human studies of prepulse inhibition of startle: normal subjects, patient groups, and pharmacological studies. Psychopharmacology (Berl) 156, 234-258.

Branchi, I., Ricceri, L., 2004. Refining learning and memory assessment in laboratory rodents. An ethological perspective. Ann. Ist Super Sanita 40, 231-236.

Bremner, J.D., Krystal, J.H., Southwick, S.M., Charney, D.S., 1996. Noradrenergic mechanisms in stress and anxiety.1. Preclinical studies. Synapse 23, 28-38.

Brimberg, L., Benhar, I., Mascaro-Blanco, A., Alvarez, K., Lotan, D., Winter, C., Klein, J., Moses, A.E., Somnier, F.E., Leckman, J.F., Swedo, S.E., Cunningham, M.W., Joel, D., 2012. Behavioral, Pharmacological, and Immunological Abnormalities after Streptococcal Exposure: A Novel Rat Model of Sydenham Chorea and Related Neuropsychiatric Disorders. Neuropsychopharmacology 37, 2076-2087.

Bronfeld, M., Bar-Gad, I., 2012. Tic Disorders: What Happens in the Basal Ganglia? Neuroscientist 19, 101-108.

Bullen, J.G., Hemsley, D.R., 1983. Sensory experience as a trigger in Gilles de la Tourette's syndrome. J. Behav. Therap. Exp. Psychiatry 14, 197-201.

Burd, L., Severud, R., Klug, M.G., Kerbeshian, J., 1999. Prenatal and perinatal risk factors for Tourette disorder. J. Perinatal Med. 27, 295-302.

Calcagni, E., Elenkov, I., 2006. Stress system activity, innate and T helper cytokines, and susceptibility to immune-related diseases. Basic Clin. Aspects Neuroendocrine Immunol. Rheum. Dis. 1069, 62-76.

Campbell, K.M., McGrath, M.J., Burton, F.H., 1999. Behavioral effects of cocaine on a transgenic mouse model of cortical-limbic compulsion. Brain Res. 833, 216-224.

Canal, C.E., Morgan, D., 2012. Head-twitch response in rodents induced by the hallucinogen 2,5-dimethoxy-4-iodoamphetamine: a comprehensive history, a re-evaluation of mechanisms, and its utility as a model. Drug Test. Anal. 4, $556-576$

Capone, F., Adriani, W., Shumilina, M., Izykenova, G., Granstrem, O., Dambinova, S., Laviola, G., 2008. Autoantibodies against opioid or glutamate receptors are associated with changes in morphine reward and physical dependence in mice. Psychopharmacology (Berl) 197, 535-548.

Cardona, F., Orefici, G., 2001. Group A streptococcal infections and tic disorders in an Italian pediatric population. J. Pediat. 138, 71-75.

Carpenter, R.E., Watt, M.J., Forster, G.L., Overli, O., Bockholt, C., Renner, K.I., Summers, C.H., 2007. Corticotropin releasing factor induces anxiogenic locomotion in trout and alters serotonergic and dopaminergic activity. Horm. Behav. 52, 600-611.

Castellanos, F.X., Fine, E.J., Kaysen, D., Marsh, W.L., Rapoport, J.L., Hallett, M., 1996. Sensorimotor gating in boys with Tourette's syndrome and ADHD: Preliminary results. Biol. Psychiatry 39, 33-41.

Cauchi, R.J., Tarnok, Z., 2012. Genetic animal models of Tourette syndrome: The long and winding road from lab to clinic. Translational Neurosci. 3, 153-159.

Cavanna, A.E., Servo, S., Monaco, F., Robertson, M.M., 2009. The Behavioral Spectrum of Gilles de la Tourette Syndrome. J. Neuropsych. Clin. Neurosci. 21, 13-23.

Chamberlain, S.R., Blackwell, A.D., Fineberg, N.A., Robbins, T.W., Sahakian, J., 2005. The neuropsychology of obsessive compulsive disorder: the importance of failures in cognitive and behavioural inhibition as candidate endophenotypic markers. Neurosci. Biobehav. Rev. 29, 399-419.

Chappell, P., Riddle, M., Anderson, G., Scahill, L., Hardin, M., Walker, D., Cohen, D., Leckman, J., 1994. Enhanced stress responsivity of Tourette syndrome patients undergoing lumbar puncture. Biol. Psychiatry 36, 35-43.

Chen, S.-K., Tvrdik, P., Peden, E., Cho, S., Wu, S., Spangrude, G., Capecchi, M.R., 2010 Hematopoietic Origin of Pathological Grooming in Hoxb8 Mutant Mice. Cell 141, 775-785.

Chen, Y., Engidawork, E., Loidl, F., Dell'Anna, E., Goiny, M., Lubec, G., Andersson, K., Herrera-Marschitz, M., 1997. Short- and long-term effects of perinatal asphyxia on monoamine, amino acid and glycolysis product levels measured in the basal ganglia of the rat. Dev. Brain Res. 104, 19-30.

Cheon, K.A., Ryu, Y.H., Namkoong, K., Kim, C.H., Kim, J.J., Lee, J.D., 2004. Dopamine transporter density of the basal ganglia assessed with I-123 IPT SPECT in drug-naive children with Tourette's disorder. Psychiatry Res. Neuroimag. 130, $85-95$.

Comings, D.E., Comings, B.G., 1987. A controlled study of Tourette syndrome. I. Attention-deficit disorder, learning disorders, and school problems. Am. J. Hum. Genet. 41, 701-741.

Conelea, C.A., Woods, D.W., 2008. The influence of contextual factors on tic expression in Tourette's syndrome: A review. J. Psychosom. Res. 65, 487-496.
Conelea, C.A., Woods, D.W., Brandt, B.C., 2011. The impact of a stress induction task on tic frequencies in youth with Tourette Syndrome. Behav. Res. Ther. 49, 492-497.

Corbett, B.A., Mendoza, S.P., Baym, C.L., Bunge, S.A., Levine, S., 2008. Examining cortisol rhythmicity and responsivity to stress in children with Tourette syndrome. Psychoneuroendocrinology 33, 810-820.

Crider, A., 1997. Perseveration in schizophrenia. Schizophrenia Bull. 23, 63-74.

Cromwell, H.C., Berridge, K.C., 1996. Implementation of action sequences by a neostriatal site: A lesion mapping study of grooming syntax. J. Neurosci. 16 3444-3458.

Cromwell, H.C., Berridge, K.C., Drago, J., Levine, M.S., 1998. Action sequencing is impaired in D-1A-deficient mutant mice. Euro. J. Neurosci. 10, 2426-2432.

Dale, R.C., 2003. Autoimmunity and the basal ganglia: new insights into old diseases. Qjm-an Int. J. Med. 96, 183-191.

Dantzer, R., 1986. Behavioral, physiological and functional aspects of stereotyped behavior: a review and a re-interpretation. J. Anim. Sci. 62, 1776-1786.

Dantzer, R., Kelley, K.W., 1989. Stress and immunity: an integrated view of relationships between the brain and the immune system. Life Sci. 44, 1995-2008.

Davison, K., 2012. Autoimmunity in psychiatry. Br. J. Psychiatry 200, 353-355.

Denckla, M.B., 2006. Attention-deficit hyperactivity disorder (ADHD) comorbidity: A case for "pure" Tourette syndrome? J. Child Neurol. 21, 701-703.

Deng, H., Gao, K., Jankovic, J., 2012. The genetics of Tourette syndrome. Nat. Rev. Neurol. 8, 203-213.

Dluzen, D.E., Anderson, L.I., McDermott, J.L., Kucera, J., Walro, J.M., 2002. Striatal dopamine output is compromised within +/- BDNF mice. Synapse 43, $112-117$.

Domeney, A., Feldon, J., 1998. The disruption of prepulse inhibition by social isolation in the Wistar rat: how robust is the effect? Pharmacol. Biochem. Behav. 59, 883-890.

Ercan-Sencicek, A.G., Stillman, A.A., Ghosh, A.K., Bilguvar, K., O`Roak, B.J., Mason, C.E., Abbott, T., Gupta, A., King, R.A., Pauls, D.L., Tischfield, J.A., Heiman, G.A., Singer, H.S., Gilbert, D.L., Hoekstra, P.J., Morgan, T.M., Loring, E., Yasuno, K., Fernandez, T., Sanders, S., Louvi, A., Cho, J.H., Mane, S., Colangelo, C.M., Biederer, T., Lifton, R.P., Gunel, M., State, M.W., 2010. L-Histidine Decarboxylase and Tourette's Syndrome. N. Engl. J. Med. 362, 1901-1908.

Evers, R.A.F., Vandewetering, B.J.M., 1994. A treatment model for motor tics based on a specific tension-reduction technique. J. Behav. Therapy Exp. Psychiatry 25, 255-260.

Felling, R.J., Singer, H.S., 2011. Neurobiology of Tourette Syndrome: Current Status and Need for Further Investigation. J. Neurosci. 31, 12387-12395.

Frank, M., Cavanna, A.E., 2012. Behavioural treatments for Tourette syndrome: An evidence-based review. Behav. Neurol., in press.

Garner, J.P., 2005. Stereotypies and other abnormal repetitive behaviors: Potential impact on validity, reliability, and replicability of scientific outcomes. Ilar J. 46, 106-117.

Garner, J.P., Dufour, B., Gregg, L.E., Weisker, S.M., Mench, J.A., 2004a. Social and husbandry factors affecting the prevalence and severity of barbering ('whisker trimming') by laboratory mice. Appl. Anim. Behav. Sci. 89, 263-282.

Garner, J.P., Mason, G.J., 2002. Evidence for a relationship between cage stereotypies and behavioural disinhibition in laboratory rodents. Behav. Brain Res. 136 83-92.

Garner, J.P., Meehan, C.L., Mench, J.A., 2003. Stereotypies in caged parrots, schizophrenia and autism: evidence for a common mechanism. Behav. Brain Res. 145, 125-134.

Garner, J.P., Thogerson, C.M., Wuerbel, H., Murray, J.D., Mench, J.A., 2006. Anima neuropsychology: Validation of the Intra-Dimensional Extra-Dimensional set shifting task for mice. Behav. Brain Res. 173, 53-61.

Garner, J.P., Weisker, S.M., Dufour, B., Mench, J.A., 2004b. Barbering (Fur and whisker trimming) by laboratory mice as a model of human trichotillomania and obsessive-compulsive spectrum disorders. Comp. Med. 54, 216-224.

Geyer, M.A., Markou, A., 1995. Animal Models of Psychiatric Disorders. Raven Press, New York 787-798.

Gilbert, D.L., Bansal, A.S., Sethuraman, G., Sallee, F.R., Zhang, J., Lipps, T., Wassermann, E.M., 2004. Association of cortical disinhibition with tic, ADHD, and OCD severity in Tourette syndrome. Mov. Disord. 19, 416-425.

Gilbert, D.L., Dure, L., Sethuraman, G., Raab, D., Lane, J., Sallee, F.R., 2003. Tic reduction with pergolide in a randomized controlled trial in children. Neurology 60 606-611.

Gittis, A.H., Leventhal, D.K., Fensterheim, B.A., Pettibone, J.R., Berke, J.D., Kreitzer, A.C., 2011. Selective Inhibition of Striatal Fast-Spiking Interneurons Causes Dyskinesias. J. Neurosci. 31, 15727-15731.

Gonce, M., Barbeau, A., 1977. Seven cases of Gilles de la tourette's syndrome: partial relief with clonazepam: a pilot study. Can. J. Neurol. Sci. Le journal canadien des sciences neurologiques 4, 279-283.

Grados, M.A., Mathews, C.A., 2009. Clinical phenomenology and phenotype variability in Tourette syndrome. J. Psychosom. Res. 67, 491-496.

Grados, M.A., Mathews, C.A., Tourette Syndrome Assoc Int, C, 2008. Latent class analysis of Gilles de la Tourette syndrome using comorbidities: Clinical and genetic implications. Biol. Psychiatry 64, 219-225.

Graham, F.K., 1975. Presidential Address, 1974. The more or less startling effects of weak prestimulation. Psychophysiology 12, 238-248.

Greer, J.M., Capecchi, M.R., 2002. Hoxb8 is required for normal grooming behavior in mice. Neuron 33, 23-34.

Gross, A.N., Engel, A.K.J., Richter, S.H., Garner, J.P., Wuerbel, H., 2011. Cage-induced stereotypies in female ICR CD-1 mice do not correlate with recurrent perseveration. Behav. Brain Res. 216, 613-620. 
Gross, A.N., Richter, S.H., Engel, A.K.J., Wuerbel, H., 2012. Cage-induced stereotypies, perseveration and the effects of environmental enrichment in laboratory mice. Behav. Brain Res. 234, 61-68.

Halberstadt, A.L., Koedood, L., Powell, S.B., Geyer, M.A., 2011. Differential contributions of serotonin receptors to the behavioral effects of indoleamine hallucinogens in mice. J. Psychopharmacol. 25, 1548-1561.

Hallett, J.J., Harling-Berg, C.J., Knopf, P.M., Stopa, E.G., Kiessling, L.S., 2000. Anti-striatal antibodies in Tourette syndrome cause neuronal dysfunction. J. Neuroimmunol. 111, 195-202.

Hartmann, A., Worbe, Y., 2012. Pharmacological treatment of Gilles de la Tourette syndrome. Neurosci. Biobehav. Rev..

Hoekstra, P.J., Kallenberg, C.G.M., Korf, J., Minderaa, R.B., 2002. Is Tourette's syndrome an autoimmune disease? Mol. Psychiatry 7, 437-445.

Hoffman, K.L., Hornig, M., Yaddanapudi, K., Jabado, O., Lipkin, W.I., 2004. A murine model for neuropsychiatric disorders associated with group A beta-hemolytic streptococcal infection. J. Neurosci. 24, 1780-1791.

Hornig, M., Lipkin, W.I., 2013. Immune-mediated animal models of Tourette syndrome. Neurosci. Biobehav. Rev..

Huber, L., Ferdin, M., Holzmann, J., Stubbusch, J., Rohrer, H., 2012. HoxB8 in noradrenergic specification and differentiation of the autonomic nervous system. Dev. Biol. 363, 219-233.

Hwang, G.C., Tillberg, C.S., Scahill, L., 2012. Habit reversal training for children with tourette syndrome: update and review. J. Child Adolesc. Psychiat. Nurs.: Official Pub. Assoc. Child Adolescent Psychiatric Nurses, Inc 25, $178-183$.

Hyde, T.M., Aaronson, B.A., Randolph, C., Rickler, K.C., Weinberger, D.R., 1992. Relationship of birth-weight to the phenotypic expression of Gilles-de-la-Tourette's syndrome in monozygotic twins. Neurology 42, 652-658.

Jeong, Y.H., Kim, J.M., Yoo, J., Lee, S.H., Kim, H.-S., Suh, Y.-H., 2011. Environmental enrichment compensates for the effects of stress on disease progression in Tg2576 mice, an Alzheimer's disease model. J. Neurochem. 119, 1282-1293.

Kajiwara, Y., Buxbaum, J.D., Grice, D.E., 2009. SLITRK1 Binds 14-3-3 and Regulates Neurite Outgrowth in a Phosphorylation-Dependent Manner. Biol. Psychiatry $66,918-925$.

Kalanithi, P., Zheng, W., Kataoka, Y., DiFiglia, M., Grantz, H., Saper, C., Schwartz, M., Leckman, J., Vaccarino, F., 2005. Altered parvalbumin-positive neuron distribution in basal ganglia of individuals with Tourette syndrome. Proc. Natl. Acad. Sci. U.S.A. 102, 13307-13312.

Karler, R., Calder, L.D., Thai, D.K., Bedingfield, J.B., 1998. The role of dopamine and GABA in the frontal cortex of mice in modulating a motor-stimulant effect of amphetamine and cocaine. Pharmacol. Biochem. Behav. 60, 237-244.

Kataoka, Y., Kalanithi, P.S.A., Grantz, H., Schwartz, M.L., Saper, C., Leckman, J.F., Vaccarino, F.M., 2010. Decreased Number of Parvalbumin and Cholinergic Interneurons in the Striatum of Individuals with Tourette Syndrome. J. Comp. Neurol. 518, 277-291.

Katayama, K., Yamada, K., Ornthanalai, V.G., Inoue, T., Ota, M., Murphy, N.P., Aruga, J., 2010. Slitrk1-deficient mice display elevated anxiety-like behavior and noradrenergic abnormalities. Mol. Psychiatry 15, 177-184.

Kawikova, I., Grady, B.P.X., Tobiasova, Z., Zhang, Y., Vojdani, A., Katsovich, L., Richmand, B.J., Park, T.W., Bothwell, A.L.M., Leckman, J.F., 2010. Children with Tourette's Syndrome May Suffer Immunoglobulin A Dysgammaglobulinemia: Preliminary Report. Biol. Psychiatry 67, 679-683.

Kawikova, I., Leckman, J.F., Kronig, H., Katsovich, L., Bessen, D.E., Ghebremichael, M., Bothwell, A.L.M., 2007. Decreased numbers of regulatory T cells suggest impaired immune tolerance in children with Tourette syndrome: A preliminary study. Biol. Psychiatry 61, 273-278.

Kay, G., Tarcic, N., Poltyrev, T., Weinstock, M., 1998. Prenatal stress depresses immune function in rats. Physiol. Behav. 63, 397-402.

Kirvan, C.A., Swedo, S.E., Snider, L.A., Cunningham, M.W., 2006. Antibodymediated neuronal cell signaling in behavior and movement disorders. J. Neuroimmunol. 179, 173-179.

Kodsi, M.H., Swerdlow, N.R., 1997. Regulation of prepulse inhibition by ventral pallidal projections. Brain Res. Bull. 43, 219-228.

Kohman, R.A., Tarr, A.J., Day, C.E., McLinden, K.A., Boehm, G.W., 2008. Influence of prenatal stress on behavioral, endocrine, and cytokine responses to adulthood bacterial endotoxin exposure. Behav. Brain Res. 193, 257-268.

Korff, S., Harvey, B.H., 2006. Animal models of obsessive-compulsive disorder: Rationale to understanding psychobiology and pharmacology. Psychiat. Clin. N. Am. 29, 371-390.

Kubota, Y., Ito, C., Sakurai, E., Watanabe, T., Ohtsu, H., 2002. Increased methamphetamine-induced locomotor activity and behavioral sensitization in histamine-deficient mice. J. Neurochem. 83, 837-845.

Kurien, B.T., Gross, T., Scofield, R.H., 2005. Barbering in mice: a model for trichotillomania. Br. Med. J. 331, 1503-1505.

Kurlan, R., 2010. Tourette's Syndrome. N. Engl. J. Med. 363, 2332-2338.

Kurlan, R., McDermott, M.P., Deeley, C., Como, P.G., Brower, C., Eapen, S., Andresen, E.M., Miller, B., 2001. Prevalence of tics in schoolchildren and association with placement in special education. Neurology 57, 1383-1388.

Landau, Y.E., Steinberg, T., Richmand, B., Leckman, J.F., Apter, A., 2012. Involvement of immunologic and biochemical mechanisms in the pathogenesis of Tourette's syndrome. J. Neural Trans. 119, 621-626.

Langen, M., Kas, M.J.H., Staal, W.G., van Engeland, H., Durston, S., 2011. The neurobiology of repetitive behavior: Of mice. Neurosci. Biobehav. Rev. 35, 345-355.

Laviola, G., Adriani, W., Rea, M., Aloe, L., Alleva, E., 2004. Social withdrawal, neophobia, and stereotyped behavior in developing rats exposed to neonatal asphyxia. Psychopharmacology (Berl) 175, 196-205.
Laviola, G., Hannan, A.J., Macri, S., Solinas, M., Jaber, M., 2008. Effects of enriched environment on animal models of neurodegenerative diseases and psychiatric disorders. Neurobiol. Dis. 31, 159-168.

Lawson-Yuen, A., Saldivar, J.-S., Sommer, S., Picker, J., 2008. Familial deletion within NLGN4 associated with autism and Tourette syndrome. Eur. J. Hum. Genet. 16 , 614-618.

Leckman, J.F., Bloch, M.H., Scahill, L., King, R.A., 2006. Tourette syndrome: The self under siege. J. Child Neurol. 21, 642-649.

Leckman, J.F., Bloch, M.H., Smith, M.E., Larabi, D., Hampson, M., 2010. Neurobiological Substrates of Tourette's Disorder. Journal of Child and. Adolesc Psychopharmacol. 20, 237-247.

Leckman, J.F., Dolnansky, E.S., Hardin, M.T., Clubb, M., Walkup, J.T., Stevenson, J., Pauls, D.L., 1990. Perinatal factors in the expression of Tourette's Syndrome An exploratory study. J. Am. Acad. Child Adolesc. Psychiatry 29, 220-226.

Leckman, J.F., Hardin, M.T., Riddle, M.A., Stevenson, J., Ort, S.I., Cohen, D.J., 1991. Clonidine treatment of Gilles-de-la-Tourette's syndrome. Arch. Gen. Psychiatry $48,324-328$.

Leckman, J.F., Katsovich, L., Kawikova, L., Lin, H.Q., Zhang, H.P., Kronig, H., Morshed, S., Parveen, S., Grantz, H., Lombroso, P.J., King, R.A., 2005. Increased serum levels of interleukin-12 and tumor necrosis factor-alpha in Tourette's syndrome. Biol. Psychiatry 57, 667-673.

Leckman, J.F., Peterson, B.S., 1993. The pathogenesis of Tourette's syndrome: epigenetic factors active in early CNS development. Biol. Psychiatry 34, 425-427.

Leckman, J.F., Price, R.A., Walkup, J.T., Ort, S., Pauls, D.L., Cohen, D.J., 1987. Nongenetic factors in Gilles de la Tourette's syndrome. Arch. Gen. Psychiatry 44, 100.

Leckman, J.F., Walker, D.E., Cohen, D.J., 1993. Premonitory urges in Tourette's syndrome. Am. J. Psychiatry 150, 98-102.

Lemaire, V., Koehl, M., Le Moal, M., Abrous, D.N., 2000. Prenatal stress produces learning deficits associated with an inhibition of neurogenesis in the hippocampus. Proc. Natl. Acad. Sci. U.S.A. 97, 11032-11037.

Lewis, M.H., 2004. Environmental complexity and central nervous system development and function. Mental Retard. Dev. Disabil. Res. Rev. 10, 91-95.

Lewis, M.H., Bodfish, J.W., 1998. Repetitive behavior disorders in autism. Mental Retard. Dev. Disabil. Res. Rev. 4, 80-89.

Lewis, M.H., Gluck, J.P., Beauchamp, A.J., Keresztury, M.F., Mailman, R.B., 1990. Longterm effects of early social isolation in Macaca mulatta: changes in dopamine receptor function following apomorphine challenge. Brain Res. 513, 67-73.

Li, J., Li, Z., Li, A., Wang, S., Qi, F., Zhao, L., Lv, H., 2010. Abnormal expression of dopamine and serotonin transporters associated with the pathophysiologic mechanism of Tourette syndrome. Neurol. India 58, 523-529.

Li, M., Wang, M., Ding, S., Li, C., Luo, X., 2012. Environmental Enrichment during Gestation Improves Behavior Consequences and Synaptic Plasticity in Hippocampus of Prenatal-Stressed Offspring Rats. Acta Histochem. Cytochem. 45, 157-166.

Lin, H., Katsovich, L., Ghebremichael, M., Findley, D.B., Grantz, H., Lombroso, P.J., King, R.A., Zhang, H., Leckman, J.F., 2007. Psychosocial stress predicts future symptom severities in children and adolescents with Tourette syndrome and/or obsessive-compulsive disorder. J. Child Psychol. Psychiatry 48, 157-166.

Lin, H., Williams, K.A., Katsovich, L., Findley, D.B., Grantz, H., Lombroso, P.J., King, R.A., Bessen, D.E., Johnson, D., Kaplan, E.L., Landeros-Weisenberger, A., Zhang, H., Leckman, J.F., 2010. Streptococcal Upper Respiratory Tract Infections and Psychosocial Stress Predict Future Tic and Obsessive-Compulsive Symptom Severity in Children and Adolescents with Tourette Syndrome and Obsessive-Compulsive Disorder. Biol. Psychiatry 67, 684-691.

Linhoff, M.W., Lauren, J., Cassidy, R.M., Dobie, F.A., Takahashi, H., Nygaard, H.B. Airaksinen, M.S., Strittmatter, S.M., Craig, A.M., 2009. An Unbiased Expression Screen for Synaptogenic Proteins Identifies the LRRTM Protein Family as Synaptic Organizers. Neuron 61, 734-749.

Lombroso, P.J., Mack, G., Scahill, L., King, R.A., Leckman, J.F., 1991. Exacerbation of Gilles-de-la-Tourette's syndrome associated with thermal-stress: a family study. Neurology 41, 1984-1987.

Lombroso, P.J., Scahill, L., 2008. Tourette syndrome and obsessive-compulsive disorder. Brain Dev. 30, 231-237.

Long, S.Y., 1972. Hair-nibbling and whisker-trimming as indicators of social hierarchy in mice. Anim. Behav. 20, 10-12.

Ma, Y., Mehta, S.L., Lu, B., Li, P.A., 2011. Deficiency in the inner mitochondrial membrane peptidase 2-like (Immp21) gene increases ischemic brain damage and impairs mitochondrial function. Neurobiol. Dis. 44, 270-276.

Maccari, S., Morley-Fletcher, S., 2007. Effects of prenatal restraint stress on the hypothalamus-pituitary-adrenal axis and related behavioural and neurobiological alterations. Psychoneuroendocrinology 32, S10-S15.

Macrì, S., Granstrem, O., Shumilina, M., dos Santos, F.J.A.G., Berry, A., Saso, L., Laviola G., 2009. Resilience and vulnerability are dose-dependently related to neonatal stressors in mice. Horm. Behav. 56, 391-398.

Marco, E.M., Macri, S., Laviola, G., 2011. Critical Age Windows for Neurodevelopmental Psychiatric Disorders: Evidence from Animal Models. Neurotox. Res. 19 286-307.

Marsh, R., Maia, T.V., Peterson, B.S., 2009. Functional disturbances within frontostriatal circuits across multiple childhood psychopathologies. Am. J. Psychiatry $166,664-674$.

Marshall, G.D., Agarwal, S.K., 2000. Stress, immune regulation, and immunity: Applications for asthma. Allergy Asthma Proc. 21, 241-246.

Martin, L.J., Spicer, D.M., Lewis, M.H., Gluck, J.P., Cork, L.C., 1991. Social deprivation of infant rhesus monkeys alters the chemoarchitecture of the brain: I. Subcortical regions. J. Neurosci. 11, 3344-3358.

Martino, D., Chiarotti, F., Buttiglione, M., Cardona, F., Creti, R., Nardocci, N., Orefici G., Veneselli, E., Rizzo, R., Italian Tourette Syndrome Study, G., 2011. The 
relationship between group A streptococcal infections and Tourette syndrome: a study on a large service-based cohort. Dev. Med. Child Neurol. 53, 951-957.

Martino, D., Dale, R.C., Gilbert, D.L., Giovannoni, G., Leckman, J.F., 2009. Immunopathogenic Mechanisms in Tourette Syndrome: A Critical Review. Mov. Disord. 24, 1267-1279.

Martino, D., Draganski, B., Cavanna, A., Church, A., Defazio, G., Robertson, M.M. Frackowiak, R.S.J., Giovannoni, G., Critchley, H.D., 2008. Anti-basal ganglia antibodies and Tourette's syndrome: a voxel-based morphometry and diffusion tensor imaging study in an adult population. J. Neurol. Neurosurg. Psychiatry 79, 820-822.

Mason, GJ., 1991. Stereotypies: a critical review. Anim. Behav. 41, 1015-1037.

McKenzie, G.M., Viik, K., 1975. Chemically induced chorieform activity: antagonism by GABA and EEG patterns. Exp. Neurol. 46, 229-243.

Miguel, E.C., do Rosario-Campos, M.C., Prado, H.D., do Valle, R., Rauch, S.L., Coffey, B.J., Baer, L., Savage, C.R., O‘Sullivan, R.L., Jenike, M.A., Leckman, J.F., 2000. Sensory phenomena in obsessive-compulsive disorder and Tourette's disorder. J. Clin. Psychiatry 61, 150-157.

Miller, A.M., Bansal, R., Hao, X., Sanchez-Pena, J.P., Sobel, L.J., Liu, J., Xu, D., Zhu, H., Chakravarty, M.M., Durkin, K., Ivanov, I., Plessen, K.J., Kellendonk, C.B., Peterson, B.S., 2010. Enlargement of Thalamic Nuclei in Tourette Syndrome. Arch. Gen. Psychiatry 67, 955-964.

Morer, A., Lazaro, L., Sabater, L., Massana, J., Castro, J., Graus, F., 2008. Antineuronal antibodies in a group of children with obsessive-compulsive disorder and Tourette syndrome. J. Psychiatric Res. 42, 64-68.

Morley-Fletcher, S., Rea, M., Maccari, S., Laviola, G., 2003. Environmental enrichment during adolescence reverses the effects of prenatal stress on play behaviour and HPA axis reactivity in rats. Eur. J. Neurosci. 18, 3367-3374.

Motlagh, M.G., Katsovich, L., Thompson, N., Lin, H.Q., Kim, Y.S., Scahill, L., Lombroso, P.J., King, R.A., Peterson, B.S., Leckman, J.F., 2010. Severe psychosocial stress and heavy cigarette smoking during pregnancy: an examination of the pre- and perinatal risk factors associated with ADHD and Tourette syndrome. Eur. Child Adolesc. Psychiatry 19, 755-764.

Muehlmann, A.M., Lewis, M.H., 2012. Abnormal repetitive behaviours: shared phenomenology and pathophysiology. J. Intell. Disabil. Res. 56, 427-440.

Muller, N., Kroll, B., Schwarz, M.J., Riedel, M., Straube, A., Lutticken, R., Reinert, R.R., Reineke, T., Kuhnemund, O., 2001. Increased titers of antibodies against streptococcal M12 and M19 proteins in patients with Tourette's syndrome. Psychiatry Res. 101, 187-193.

Muller, N., Riedel, M., Straube, A., Gunther, W., Wilske, B., 2000. Increased antistreptococcal antibodies in patients with Tourette's syndrome. Psychiatry Res. $94,43-49$.

Muller-Vahl, K., Kaufmann, J., Grosskreutz, J., Dengler, R., Emrich, H., Peschel, T., 2009. Prefrontal and anterior cingulate cortex abnormalities in Tourette Syndrome: evidence from voxel-based morphometry and magnetization transfer imaging. BMC Neurosci. 10, 47.

Muller-Vahl, K.R. Surgical treatment of Tourette syndrome. Neurosci. Biobehav. Rev., in press.

Murphy, T.K., Kurlan, R., Leckman, J., 2010. The immunobiology of Tourette's disorder, pediatric autoimmune neuropsychiatric disorders associated with Streptococcus, and related disorders: a way forward. J. Child. Adolesc. Psychopharmacol. 20, 317-331.

Neuner, I., Kupriyanova, Y., Stoecker, T., Huang, R., Posnansky, O., Schneider, F., Shah, N.J., 2011. Microstructure assessment of grey matter nuclei in adult tourette patients by diffusion tensor imaging. Neurosci. Lett. 487, 22-26.

Nordstrom, E.J., Burton, F.H., 2002. A transgenic model of comorbid Tourette's syndrome and obsessive-compulsive disorder circuitry. Mol. Psychiatry 7, 617-625.

O‘Rourke, J.A., Scharf, J.M., Yu, D., Pauls, D.L., 2009. The genetics of Tourette syndrome: A review. J. Psych. Res. 67, 533-545.

Ozonoff, S., Strayer, D.L., McMahon, W.M., Filloux, F., 1998. Inhibitory deficits in Tourette syndrome: a function of comorbidity and symptom severity. J. Child Psychol. Psychiatry Allied Dis. 39, 1109-1118.

Petek, E., Windpassinger, C., Vincent, J.B., Cheung, J., Boright, A.P., Scherer, S.W., Kroisel, P.M., Wagner, K., 2001. Disruption of a novel gene (IMMP2L) by a breakpoint in 7q31 associated with Tourette syndrome. Am. J. Hum. Genet. 68, $848-858$.

Peterson, B.S., 1996. Considerations of natural history and pathophysiology in the psychopharmacology of Tourette's syndrome. J. Clin. Psychiatry 57, 24-34

Peterson, B.S., Choi, H.A., Hao, X., Amat, J.A., Zhu, H., Whiteman, R., Liu, J., Xu, D., Bansal, R., 2007. Morphologic features of the amygdala and hippocampus in children and adults with Tourette syndrome. Arch. Gen. Psychiatry 64, 1281-1291.

Peterson, B.S., Staib, L., Scahill, L., Zhang, H.P., Anderson, C., Leckman, J.F., Cohen, D.J., Gore, J.C., Albert, J., Webster, R., 2001. Regional brain and ventricular volumes in Tourette syndrome. Arch. Gen. Psychiatry 58, 427-440.

Poliak, S., Gollan, L., Martinez, R., Custer, A., Einheber, S., Salzer, J.L., Trimmer, J.S., Shrager, P., Peles, E., 1999. Caspr2, a new member of the neurexin superfamily, is localized at the juxtaparanodes of myelinated axons and associates with $\mathrm{K}+$ channels. Neuron 24, 1037-1047.

Powell, S.B., Newman, H.A., Pendergast, J.F., Lewis, M.H., 1999. A rodent model of spontaneous stereotypy: Initial characterization of developmental, environmental, and neurobiological factors. Physiol. Behav. 66, 355-363.

Proenca, C.C., Gao, K.P., Shmelkov, S.V., Rafii, S., Lee, F.S., 2011. Slitrks as emerging candidate genes involved in neuropsychiatric disorders. Trends Neurosci. 34, $143-153$.

Quednow, B.B., 2008. Sensorimotor gating deficits in psychiatric disorders. Zeitschrift Fur Neuropsychologie 19, 139-163.
Randolph, C., Hyde, T.M., Gold, J.M., Goldberg, T.E., Weinberger, D.R., 1993. Tourette's syndrome in monozygotic twins. Relationship of tic severity to neuropsychological function. Arch. Neurol. 50, 725-728.

Reinhardt, V., 2005. Hair pulling: a review. Lab. Anim. 39, 361-369.

Rickard, M.D., 2004. The use of animals for research on animal diseases: Its impact on the harm-benefit analysis. Atla-Alternatives Lab. Anim. 32, 225-227.

Rizzo, R., Gulisano, M., Pavone, P., Fogliani, F., Robertson, M.M., 2006. Increased antistreptococcal antibody titers and antii-basal ganglia antibodies in patients with Tourette syndrome: Controlled cross-sectional study. J. Child Neurol. 21, 747-753.

Robertson, M.M., 2000. Tourette syndrome, associated conditions and the complexities of treatment. Brain 123, 425-462.

Robertson, M.M., 2006a. Attention deficit hyperactivity disorder, tics and Tourette's syndrome: the relationship and treatment implications. A commentary. Eur. Child Adolesc. Psychiatry 15, 1-11.

Robertson, M.M., 2006b. Mood disorders and Gilles de la Tourette's syndrome: an update on prevalence, etiology, comorbidity, clinical associations, and implications. J. Psychosom. Res. 61, 349-358.

Rollnik, J.D., Schubert, M., Dengler, R., 2000. Effects of a competitive stressor on motor cortex excitability: a pilot study. Stress Med. 16, 49-54.

Sacks, O., 2008. Musicophilia: Tales Music Brain.

Sarter, M., Bruno, J.P., 2002. Animal Models in Biological Psychiatry. John Wiley.

Scahill, L., Erenberg, G., Berlin Jr., C.M., Budman, C., Coffey, B.J., Jankovic, J., Kiessling, L., King, R.A., Kurlan, R., Lang, A., Mink, J., Murphy, T., Zinner, S., Walkup, J. Tourette Syndrome Association Medical Advisory Board: Practice, C., 2006. Contemporary assessment and pharmacotherapy of Tourette syndrome. NeuroRx: J. Am. Soc. Exp. NeuroTherapeut. 3, 192-206.

Scheel-Kruger, J., Arnt, J., Magelund, G., 1977. Behavioural stimulation induced by muscimol and other GABA agonists injected into the substantia nigra. Neurosci. Lett. 4, 351-356.

Schilling, G., Savonenko, A.V., Coonfield, M.L., Morton, J.L., Vorovich, E., Gale, A., Neslon, C., Chan, N., Eaton, M., Fromholt, D., Ross, C.A., Borchelt, D.R., 2004. Environmental, pharmacological, and genetic modulation of the HD phenotype in transgenic mice. Exp. Neurol. 187, 137-149.

Sheppard, D.M., Bradshaw, J.L., Purcell, R., Pantelis, C., 1999. Tourette's and Comorbid syndromes: Obsessive compulsive and attention deficit hyperactivity disorder. A common etiology? Clin. Psychol. Rev. 19, 531-552.

Shprecher, D., Kurlan, R., 2009. The Management of Tics. Mov. Disord. 24, 15-24.

Singer, H.S., 2005. Tourette's syndrome: from behaviour to biology. Lancet Neurol. 4, 149-159.

Singer, H.S., 2009. Motor Stereotypies. Semin. Pediatric Neurol. 16, 77-81.

Singer, H.S., Butler, I.J., Tune, L.E., Seifert Jr., W.E., Coyle, J.T., 1982. Dopaminergic dsyfunction in Tourette syndrome. Ann. Neurol. 12, 361-366.

Singer, H.S., Minzer, K., 2003. Neurobiology of Tourette's syndrome: concepts of neuroanatomic localization and neurochemical abnormalities. Brain Dev. 25 S70-S84.

Sowell, E., Kan, E., Yoshii, J., Thompson, P., Bansal, R., Xu, D., Toga, A., Peterson, B., 2008. Thinning of sensorimotor cortices in children with Tourette syndrome. Nat. Neurosci. 11, 637-639.

Spencer, T.J., Biederman, J., Mick, E., 2007. Attention-Deficit/Hyperactivity disorder: Diagnosis, lifespan, comorbidities, and neurobiology. J. Pediatric Psychol. 32, 631-642.

State, M.W, 2011. The genetics of Tourette disorder Curr. Opin. Genet. Dev. 21, 302-309.

Stewart, L.S., Cortez, M.A., Snead III, O.C., 2012. Environmental Enrichment Improves Behavioral Outcome in the AY-9944 Model of Childhood Atypical Absence Epilepsy. Int. J. Neurosci. 122, 449-457.

Stillman, A.A., Krsnik, Z., Sun, J., Rasin, M.-R., State, M.W., Sestan, N., Louvi, A., 2009. Developmentally Regulated and Evolutionarily Conserved Expression of SLITRK1 in Brain Circuits Implicated in Tourette Syndrome. J. Comp. Neurol. 513, 21-37.

Swain, J.E., Scahill, L., Lombroso, P.J., King, R.A., Leckman, J.F., 2007. Tourette syndrome and tic disorders: A decade of progress. J. Am. Acad. Child Adolesc. Psychiatry 46, 947-968.

Swedo, S.E., Leonard, H.L., Garvey, M., Mittleman, B., Allen, A.J., Perlmutter, S., Dow, S., Zamkoff, J., Dubbert, B.K., Lougee, L., 1998. Pediatric autoimmune neuropsychiatric disorders associated with streptococcal infections: Clinical description of the first 50 cases. Am. J. Psychiatry 155, 264-271.

Swerdlow, N.R. Update: Studies of prepulse inhibition of startle, with particular relevance to the pathophysiology or treatment of Tourette Syndrome. Neurosci. Biobehav. Rev., in press.

Swerdlow, N.R., Bongiovanni, M.J., Tochen, L., Shoemaker, J.M., 2006. Separable noradrenergic and dopaminergic regulation of prepulse inhibition in rats: implications for predictive validity and Tourette Syndrome. Psychopharmacology (Berl) 186, 246-254

Swerdlow, N.R., Geyer, M.A., 1998. Using an animal model of deficient sensorimotor gating to study the pathophysiology and new treatments of schizophrenia. Schizophrenia Bull. 24, 285-301.

Swerdlow, N.R., Geyer, M.A., Braff, D.L., 2001. Neural circuit regulation of prepulse inhibition of startle in the rat: current knowledge and future challenges. Psychopharmacology (Berl) 156, 194-215.

Swerdlow, N.R., Sutherland, A.N., 2005. Using animal models to develop therapeutics for Tourette Syndrome. Pharmacol. Therap. 108, 281-293.

Tanaka, S., Young, J.W., Gresack, J.E., Geyer, M.A., Risbrough, V.B., 2011. Factor analysis of attentional set-shifting performance in young and aged mice. Behav. Brain Func. 7, 33. 
G Model

NBR-1740; No. of Pages 16

16

S. Macrì et al. / Neuroscience and Biobehavioral Reviews xxx (2013) xxx-xxx

Tanimura, Y., Vaziri, S., Lewis, M.H., 2010. Indirect basal ganglia pathway mediation of repetitive behavior: Attenuation by adenosine receptor agonists. Behav. Brain Res. 210, 116-122.

Taylor, J.R., Morshed, S.A., Parveen, S., Mercadante, M.T., Scahill, L., Peterson, B.S., King, R.A., Leckman, J.F., Lombroso, P.J., 2002. An animal model of Tourette's syndrome. Am. J. Psychiatry 159, 657-660.

Turner, C.A., Lewis, M.H., 2003. Environmental enrichment: effects on stereotyped behavior and neurotrophin levels. Physiol. Behav. 80, 259-266.

Turner, M., 1997. Towards an executive dysfunction account of repetitive behaviour in autism. In: Russell, J. (Ed.), Autism as an Executive Disorder. Oxford University Press, Oxford, pp. 839-849.

van der Staay, F.J., 2006. Animal models of behavioral dysfunctions: Basic concepts and classifications, and an evaluation strategy. Brain Res. Rev. 52, 131-159.

van der Staay, F.J., Arndt, S.S., Nordquist, R.E., 2009. Evaluation of animal models of neurobehavioral disorders. Behav. Brain Func. 5, 11.

Vandebroek, I., Berckmoes, V., Odberg, F.O., 1998. Dissociation between MK-801and captivity-induced stereotypies in bank voles. Psychopharmacology (Berl) $137,205-214$.

Verkerk, A., Mathews, C.A., Joosse, M., Eussen, B.H.J., Heutink, P., Oostra, B.A., Tourette Syndrome Assoc Int, C., 2003. CNTNAP2 is disrupted in a family with Gilles de la Tourette syndrome and obsessive compulsive disorder. Genomics 82, 1-9.

Vicario, C.M., Martino, D., Spata, F., Defazio, G., Giacche, R., Martino, V., Rappo, G., Pepi, A.M., Silvestri, P.R., Cardona, F., 2010. Time processing in children with Tourette's syndrome. Brain Cogn. 73, 28-34.

Vickery, S.S., Mason, G.J., 2005a. Behavioral persistence in captive bears: response to Criswell and Galbreath. Ursus 16, 274-279.

Vickery, S.S., Mason, G.J., 2005b. Stereotypy and perseverative responding in caged bears: further data and analyses. Appl. Anim. Behav. Sci. 91, 247-260.
Willner, P., 1984. The validity of animal models of depression. Psychopharmacology (Berl) 83, 1-16.

Willner, P., Mitchell, P.J., 2002. Animal Models of Depression: A Diathesis/Stress Approach. John Wiley, UK, 703-726.

Wood, B.L., Klebba, K., Gbadebo, O., Lichter, D., Kurlan, R., Miller, B., 2003. Pilot study of effect of emotional stimuli on tic severity in children with Tourette's syndrome. Mov. Disord. 18, 1392-1395.

Wurbel, H., Chapman, R., Rutland, C., 1998. Effect of feed and environmental enrichment on development of stereotypic wire-gnawing in laboratory mice. Appl. Anim. Behav. Sci. 60, 69-81.

Wurbel, H., Stauffacher, M., vonHolst, D., 1996. Stereotypies in laboratory mice Quantitative and qualitative description of the ontogeny of 'wire-gnawing' and 'jumping' in Zur:ICR and Zur:ICR nu. Ethology 102, 371-385.

Yaddanapudi, K., Hornig, M., Serge, R., De Miranda, J., Baghban, A., Villar, G., Lipkin, W.I., 2010. Passive transfer of streptococcus-induced antibodies reproduces behavioral disturbances in a mouse model of pediatric autoimmune neuropsychiatric disorders associated with streptococcal infection. Mol. Psychiatry $15,712-726$.

Zhang, C., Milunsky, J.M., Newton, S., Ko, J., Zhao, G., Maher, T.A., Tager-Flusberg, H., Bolliger, M.F., Carter, A.S., Boucard, A.A., Powell, C.M., Suedhof, T.C., 2009. A Neuroligin-4 Missense Mutation Associated with Autism Impairs Neuroligin-4 Folding and Endoplasmic Reticulum Export. J. Neurosci. 29, 10843-10854.

Zhuang, X.X., Oosting, R.S., Jones, S.R., Gainetdinov, R.R., Miller, G.W., Caron, M.G., Hen, R., 2001. Hyperactivity and impaired response habituation in hyperdopaminergic mice. Proc. Natl. Acad. Sci. U.S.A. 98, 1982-1987.

Ziemann, U., Paulus, W., Rothenberger, A., 1997. Decreased motor inhibition in Tourette's disorder: Evidence from transcranial magnetic stimulation. Am. J. Psychiatry 154, 1277-1284.

Please cite this article in press as: Macrì, S., et al., Theoretical and practical considerations behind the use of laboratory animals for the study of Tourette syndrome. Neurosci. Biobehav. Rev. (2013), http://dx.doi.org/10.1016/j.neubiorev.2013.03.014 